\title{
Trade Costs, Global Value Chains and ECONOMIC DEVELOPMENT ${ }^{\mathrm{a}}$
}

\author{
Yuan $\mathrm{Zi}^{\mathrm{b}}$
}

\begin{abstract}
This paper develops a model with sequential production stages and international trade frictions that permits an analysis of how decreases in trade costs shape the interdependence between countries, with special focus on the joining and industrialization pattern of developing countries into the global value chains (GVCs). I show that in a two-country setting, a decrease in trade costs of intermediates is associated with South moving up the value chain and both North and South experiencing welfare improvement, combined with a non-linear wage response. Then I extend the model into a multi-country setting with two simple thought experiments. I show that when global trade frictions fall, South countries join supply-chain networks due to wage differentials and low trade costs; this increases the North wage but may decrease the wages of an insider South. In addition, "Factory South" are regionally clustered. The model provides a first look at GVCs from the development angle, and raises several interesting policy concerns regarding GVC governance.
\end{abstract}

\footnotetext{
${ }^{\mathrm{a}} \mathrm{I}$ am in debt to Richard Baldwin, my supervisor, for his patient supervision and valuable suggestions. I am grateful to Nicolas Berman, Frédéric Robert-Nicoud, and Ugo Panizza for helpful comments and suggestions. I especially thank my colleagues Aksel Erbahar and Stela Rubínová for taking time to discuss and proofread this paper.

${ }^{\mathrm{b}}$ Graduate Institute of International and Development Studies, Geneva. yuan.zi@graduateinstitute.ch.
}

(C) The Authors.

All rights reserved. No part of this publication may be reproduced without the permission of the authors.

http://graduateinstitute.ch/ctei 



\section{Introduction}

The new development agenda influenced by supply-chain trade has attracted significant attention among policy makers and academics in the past decades (OECD, 2013, 2007).While countries that followed the old development strategy trying to build complete and complex industries struggled with economic stagnation, other countries actively engaged in international production sharing experienced rapid economic growth. Most astonishing stories happened in East Asia: in less than a decade, joining global supply chains has transformed several East Asian industries from uncompetitive, tariff-sheltered relics into world-class exporters (Baldwin, 2011).

On the academic side, though the literature on fragmented production is large and diverse,${ }^{c}$ a tractable theory that can be used to analyze how the "second global unbundling, ${ }^{\text {, }}$ (Baldwin, 2006) reshaped the development opportunities and challenges for under-developed nations is missing. This paper aims to fill this gap by trying to answer the following questions: how does a decrease in trade costs enables a South nation ${ }^{\mathrm{e}}$ to develop via joining the global value chains (GVCs) and what is the implication for wages, production complexity and international inequality? In a multi-country setting, if global trade costs fall steadily due to the Information and Communication Technology (ICT) revolution, which South countries will join the global supply-chain networks first? And followed by whom? What will be the structure of production networks and how will the welfare of insiders depend on new participants of the GVCs?

To tackle these questions, I develop a model with sequential production stages and international trade frictions to analyze how a decrease in trade costs shapes the interdependence between countries. I begin in Section 2 by developing a benchmark twocountry model. I assume that there are two alternative ways of organizing production: modern and traditional. The modern-production involves sequential stages of production with each firm specializing in one stage à la Costinot et al. (2013). Given the basic setup, I show that with the presence of trade costs, there exists a unique equilibrium which involves international production sharing. Moreover, in this equilibrium, it is always the North that specializes in later stages while the South specializes in early stages of the production process due to differences in technological efficiency.

With this result at hand, the rest of Section 2 focuses on examining how a decrease in trade costs affects a developing nation's joining and moving up the value chain. Initially, I assume that there is no trade in intermediate goods between the North and South due to high

\footnotetext{
${ }^{\mathrm{c}}$ See for instance, Antras and Rossi-Hansberg (2008) for literature reviews.

' Baldwin (2006) refers to the industrial revolution in the 18th century as the 'first unbundling.'

${ }^{\mathrm{e}}$ In this paper, I refer to developing/less-developed countries as South, and developed countries as North.
} 
trade costs. The North has the modern sector while the South produces using traditional technology only. As trade costs go down, the model predicts that the industrialization process of the South consists of two episodes. The first episode is characterized by the specialization of North in high-end intermediates and an expansion of modern industry in the South. This is associated with labor in the South moving from the traditional to the modern sector à la Lewis (1954). During this period, there is no real wage improvement in the South even though it operates increasingly in complicated stages, and wage inequality between North and South rises. The second episode starts from the modern sector in the South absorbing all of the country's labor force. In this period, a decrease in trade costs is associated with the South moving up the value chain and the hollowing out of North's industry base; real wage increases for both countries, and global income inequality decreases.

Section 3 extends the model to a multi-country setting. In this environment, countries vary in efficiency, and trade costs are country-pair specific. After providing formal definitions to distinguish "value chain" and "supply-chain networks", I prove that despite the possible complex nature of global supply-chain networks, the ordering of countries along each value chain strictly follows their "efficiency ordering." Furthermore, I identify conditions for an outside nation to successfully join a value chain. In particular, the joining condition is much more restrictive for countries that have no modern industry compared to countries that have an industry base: a country that has a modern sector can successfully join as long as its trade friction to any nation already in the chain is low enough; while for a country with no modern industry, its success in joining a value chain depends crucially on its proximity ${ }^{\mathrm{f}}$ to the country at the very upstream of the value chain.

After characterizing the general specialization and joining pattern, the rest of Section 3 focuses on the interdependency between developing nations. To emphasize the key insights of the model, I focus on a one-North, multiple-South setting and repeat the thought experiment of Section 2. First, I consider the case in which countries' efficiency is fixed and all South countries have the same efficiency. As trade costs decrease, South countries start to forge supply chains with the North, and the network exhibits a hub-and-spoke pattern: each South country supplies intermediates to the North without trading with other South countries. Surprisingly, even without direct interaction, South countries' welfares are closely linked: the joining of a new South country decreases the welfare of other South members of the value chain, even though every South nation moves up by operating in more stages.

In the second thought experiment, I replace the fixed-efficiency assumption by a simple learning-by-doing mechanism: South's efficiency is strictly correlated to its joining time. That is, the earlier the South joins the supply chain, the more likely its workers get proficient in

\footnotetext{
f "Proximity" refers to low bilateral trade frictions in intermediates.
} 
modern production and hence have lower defect rates (i.e. higher efficiency). This creates a flying-geese pattern of development: as trade costs fall gradually, South countries join the value chain sequentially with the latest specializing at the upstream stage of the value chain. In this case, if the learning by doing effect is strong enough, the joining of a new South country benefits everyone in the value chain and a global decrease in trade frictions leads to all countries moving up, as well as improving the real wage of all nations. In both cases, the joining pattern of new South depends on its proximity to South countries that are already inside the value chain, which implies that factory economies ${ }^{\mathrm{g}}$ are likely to be regionally clustered.

This paper is motivated by recent discussions on how supply-chain trade has transformed the development strategy and trade policy of developing countries. Important works include Gereffi et al. (2005), Baldwin (2011) and Baldwin (2012). My paper contributes to this strand of the literature by providing a tractable theoretical framework that formalizes the analysis. The model yields new insights and raises new questions that have been overlooked. The paper is also inspired by recent empirical literature on supply-chain trade, such as Hummels et al. (1998), Hummels et al. (2001), Koopman et al. (2010), Johnson and Noguera (2012a), and Johnson and Noguera (2012b), and has been able to match several documented empirical regularities.

In terms of focus, this paper is related to the literature that looks at sequential production in an international context. Important papers include Findlay (1978), Sanyal and Jones (1982), Dixit and Grossman (1982), Spencer and Jones (1992), and Costinot, Vogel and Wang (2013), who emphasize the interdependency between nations and examine the transmission effect of macroeconomic shocks, technological changes and trade policies on countries' welfare, specialization pattern, trade flows, and wage inequalities. Some others, including Yi (2003), Harms et al. (2012) and Baldwin and Venables (2013) analyze interesting nonlinearities of how trade flows respond to trade frictions in a partial equilibrium setting. Other authors, including Antràs and Chor (2012), Kikuchi et al. (2012) and Fally and Hillberry (2013), discuss firm boundaries and the slicing of value chains from a property-rights prospective. Among the diverse literature, my model is mostly related to the focus of Yi (2003), Harms, Lorz and Urban (2012) and Baldwin and Venables (2013), who are interested in the implications of trade costs for international specialization and trade flows. The difference is, I discuss the issue in a general equilibrium setting and extend the analysis to multiple countries. This enables me to reveal interesting cross-country factor price adjustments and implications on further production fragmentation.

${ }^{g}$ I use the term "factory economies" to refer to developing South countries that participate in the GVCs. Accordingly developed North countries are referred to as "headquarter economies." 
In terms of modeling techniques, the article is closely related to the hierarchies literature, see for instance Sobel (1992), Kremer (1993), and Garicano (2000). It is also related to the literature on assortative matching in an international setting, see Yeaple (2005), Ohnsorge and Trefler (2007), Nocke and Yeaple (2008), and Costinot (2009), among others. In particular, the setting of the modern sector in my model is built on Costinot, Vogel and Wang (2013). The model however is novel in two key dimensions. First, I introduce bilateral trade frictions in intermediates so that some countries are excluded from GVC participation. Second, I assume that developing countries have no modern industry to start with, which puts the GVC participation and economic development in the center of the analysis. As a result, I am able to add to the previous contributions by formally analyze how the second global unbundling benefits developing nations via enabling them to industrialize through joining GVCs.

The rest of the paper is organized as follows. Section 2 presents the benchmark twocountry model and studies how specialization pattern, real wages and inequality between North and South respond to changes in trade frictions. In Section 3, I extend the model to a multi-country environment and discuss its general implications. I also describe two thought experiments that examine the joining pattern and interdependency of developing South. Section 4 discusses policy implications of the paper and Section 5 concludes. Most of the proofs in the paper are relegated to the Appendix.

\section{A Model of Sequential Production with International Trade Frictions}

I begin by developing a benchmark model of sequential production along the lines of Costinot, Vogel and Wang (2013), extended to incorporate international trade costs and decentralized firm decisions. To emphasize the new insights generated from trade frictions, I restrict my attention to a two-country model in this section.

\subsection{Basic Setup}

Consider a world with two countries, North (N) and South (S). $L_{c}$ and $w_{c}$ denote labor endowment and wage in country $c=N, S$, respectively. Labor is inelastically supplied and immobile across countries, and domestic labor markets are perfectly competitive. There is a freely traded final good which I use as numeraire. As it is the only consumption good, nominal wage equals real wage.

There are two ways of organizing production: traditional and modern. Traditional production involves a single firm producing one unit of final good using $a_{c}$ units of labor. Modern production requires firms to specialize and coordinate with each other. As in Costinot, Vogel and Wang (2013), in order to produce the final good, a continuum of stages $s \in(0,1]$ must be performed sequentially. At each stage, production of one unit of intermediate good requires one unit of labor and one unit of the intermediate good produced in the previous 
stage. Each firm occupies an infinitesimal stage of this production chain. Crucially, firms are prone to mistakes when combining intermediates with labor to produce goods for the next stage. Mistakes occur at a country-specific Poisson rate $\lambda_{c}$, and when they do happen, the intermediate good is entirely lost. Formally, suppose a firm from country $c$ is located at stage $s+d s$ (with $d s$ infinitesimal); its output $q_{c}(s+d s)$ is given by:

$$
q_{c}(s+d s)=\left(1-\lambda_{c} d s\right) q_{c}(s)
$$

where $q_{c}(s)$ is the amount of intermediate input used from previous stage $s$. Without loss of generality, I assume that $a_{S}=a_{N}=a$, and $\lambda_{S}>\lambda_{N}$. That is, while South firms are as productive as North in the traditional way of producing goods, they are less efficient in organizing the modern production process. Therefore, $\lambda$ reflects the productivity or technology difference between the North and the South in modern production. In addition, I include a regularity condition that $\frac{\lambda_{S}}{e^{\lambda_{S}-1}}<\frac{1}{a}<\frac{\lambda_{N}}{e^{\lambda_{N-1}}}{ }^{\mathrm{h}}$. This means that in aggregate, the modern production method is more efficient for the North while the opposite is true for the South. All markets are perfectly competitive.

International production sharing is subject to trade costs of the standard iceberg type. Formally, when stage $s$ and stage $s+d s$ are located in different countries, say countries $c$ and $c^{\prime}$ respectively, equation (1) becomes

$$
q_{c^{\prime}}(s+d s)=\frac{1}{\tau}\left(1-\lambda_{c} d s\right) q_{c}(s)
$$

where $\tau \in[1, \infty)$, with $\tau=1$ indicating frictionless production sharing.

Broadly speaking, I use $\tau$ to capture the "proximity" between countries in terms of coordinating international production processes. Besides standard trade barriers such as distance and tariffs, it also captures the resource loss caused by communication frictions, language and culture differences, back and forth long-distance traveling of key personnel etc.

It is worth mentioning that the iceberg trade cost is a more natural assumption when production process is vertically linked. Initially, the iceberg assumption for modeling transportation costs was introduced for practical reasons: it simplifies the analytical results when using Dixit-Stiglitz model of monopolistic competition (Dixit and Stiglitz, 1977). However, as Ottaviano and Thisse (2004) point out, the iceberg assumption implies that a rise in the price of a good leads to a proportional rise in its transportation cost, which is unlikely in most cases. While such critique is indeed valid when we consider final goods, in a sequential production setting, the iceberg assumption for intermediates is relatively more realistic: firstly, intermediates produced in later stages are more complex, with more value added, and

\footnotetext{
${ }^{\mathrm{h}}$ I set this regularity condition mainly for simplicity as the main results of the paper remain unchanged without it. The regularity condition eliminates some additional equilibria that are theoretically possible (only for section 2.2) but of little real interest for this paper.
} 
probably more fragile or with larger weight or volume. In other words, goods at later stages are likely to be more costly to trade. Secondly, when business partners are from different countries, imperfect understanding due to language differences, communication frictions, uncertainty of macro-environment etc. can lead to additional "waste" of intermediates. These issues are more likely to play important roles at later stages, as intermediates' complexity increases along the production process. Therefore in this case the proportional or iceberg trade cost assumption simply reflects that coordination frictions in later stages are higher as inputs are more complex.

\subsection{Equilibrium Analysis}

In this sub-section I characterize all feasible equilibria as a preparation for the analysis in the rest of the section. In equilibrium, all firms maximize their profit, taking price, wage and industry structure as given, and all markets clear.

In order to facilitate the exposition I first introduce some terminology. Productionsharing exists if there is any trade in intermediates between South and North. Otherwise, the world is of separate-production. Moreover, a country is specialized if it occupies at least a stage of the modern production; such specialization is incomplete if the modern sector coexists with the traditional sector-otherwise the country is completely specialized. Accordingly, if any equilibrium involves production sharing, it is a production-sharing equilibrium; otherwise it is a separate-production equilibrium. When countries trade intermediates among each other, with at least one nation having also the traditional sector, I call it incomplete production-sharing equilibrium; otherwise I call it complete productionsharing equilibrium.

In general, because of the interdependence among firms in the modern sector, characterizing all equilibria is not straightforward: the range of production stages a country occupies depends on the initial production structure it had. However, as each stage is infinitesimal and there is no strategic cooperation among firms, I am able to circumvent the industry lumpiness and obtain relatively simple results: based on the model setting, there are only three feasible equilibria ${ }^{i}$, and only one of them involves production sharing. In the production-sharing equilibrium, the North performs the downstream stages and the South occupies the upstream stages of the production process. Note that this equilibrium can be an incompletely specialized equilibrium, with the South also operating in the traditional sector. These results are summarized in Lemmas 1 and 2, respectively.

\footnotetext{
${ }^{\mathrm{i}}$ These and all subsequent proofs are included in the Appendix. Here, feasible means that there exist wages to support the equilibrium production structure in each country.
} 
Lemma 2-1. There are two feasible separate-production equilibria. In one of the equilibria, all South firms operate in the traditional sector and all North firms in the modern sector; in the other both countries' firms operate only in the traditional sector.

The intuition behind Lemma $2-1$ is simple. If all firms in country $c=N, S$ adopt the traditional production process, the equilibrium wage and total output of final goods are $\mathrm{j}^{\mathrm{j}}$ :

$$
\begin{gathered}
w_{c}=1 / a \\
Q_{c}=L_{c} / a
\end{gathered}
$$

If all firms adopt modern production technology, perfect competition requires that, for any stage $s$, the following price equation must hold:

$$
P_{c}(s+d s)=\left(1+\lambda_{c} d s\right) P(s)+w_{c} d s
$$

From equation (5), together with the price boundary condition $\mathrm{P}(0)=0, \mathrm{P}(1)=1$, it is easy to get the equilibrium wage in country $c$ :

$$
w_{c}=\frac{\lambda_{c}}{e^{\lambda_{c}}-1}
$$

Notice that $\frac{1}{a} \neq \frac{\lambda_{C}}{e^{\lambda_{C}-1}}$. Thus, before production unbundling, countries can have either the traditional industry or the modern industry, but not both. Furthermore, $\frac{1}{a}>\frac{\lambda_{S}}{e^{\lambda} S-1}$ implies that final goods will be cheaper if firms in the South operate with traditional technology. Therefore when each country produces independently, South has the traditional sector only. Also, $\frac{1}{a}<\frac{\lambda_{N}}{e^{\lambda_{N}-1}}$ suggests that final goods will be cheaper if firms in the North organize production in the modern manner. However, having solely the traditional sector is also a stable equilibrium - lacking upstream suppliers and downstream customers, no firm in the North will find it profitable to adopt the modern technology. This idea is akin to RosensteinRodan's (Rosenstein-Rodan, 1943) "simultaneous industrialization," which is presented formally by Murphy et al. (1989), among others.

With the labour market clearing condition $\int_{0}^{1} Q_{c}(s) d s=L_{c}$, the modern separateproduction equilibrium output and price in each stage $s$ can be characterized as follows:

$$
\begin{aligned}
Q_{c}(s) & =\frac{L_{c} \lambda_{c} e^{-\lambda_{c} s}}{1-e^{-\lambda_{c}}} \\
P_{c}(s) & =\frac{e^{\lambda_{c} s}-1}{e^{\lambda_{c}}-1}
\end{aligned}
$$

With some algebra one can show that output is an increasing function of country size $L_{c}$, and a decreasing function of the inefficiency measure $\lambda_{C}$. Price, on the other hand, is an increasing function of stages $s$ and a decreasing function of $\lambda_{c}$.

\footnotetext{
${ }^{\mathrm{j}}$ Without special mentioning, I use subscripts to indicate countries, brackets to indicate production stages, and $Q$ to denote final goods—in particular, $Q \equiv Q(s=1)$ for modern sector.
} 
Lemma 2-2. If international production-sharing exists, it must be that there exists a stage $\tilde{s} \in(0,1)$ such that $Q_{S}(s)>0$ if and only if $s \in(0, \tilde{s}]$; and $Q_{N}(s)>0$ if and only if $s \in$ $(\tilde{s}, 1]$. The traditional sector may co-exist with the modern sector in the South.

Lemma 2-2 explains that if there is any production sharing between North and South, it must be the case that North specializes in the downstream and South specializes in the upstream. The broad intuition behind this result is along the lines of Sobel (1992), Kremer (1993), and Costinot, Vogel and Wang (2013): as price increases along the supply chain and defect rate is always proportional to the price of intermediates, it is relatively more costly to make mistakes in the later stages. Hence the North, with lower defect odds, has a comparative advantage in producing at later stages.

When production sharing exists, as showed in the Appendix, the wage gap between North and South must satisfy the following condition:

$$
w_{N}=\tau w_{S}+\tau P(\tilde{s})\left(\lambda_{S}-\lambda_{N}\right)
$$

where $\tilde{s}$ denotes the cutoff stage of specialization, and $p(\tilde{s})$ indicates the price of intermediate good at stage $\tilde{s}$.

Equation (9) shows that the wage gap between North and South is an increasing function of trade cost $\tau$ and the technology gap between the two countries. Note that here trade costs act as a wedge to lift North wages. The higher the trade cost, the lower the price South must charge for its intermediates in order to attract North customers. This in turn implies a lower factor cost in the South. An increase in $p(\tilde{s})$ also implies a rise in the wage gap. The intuition behind this is simple: higher $p(\tilde{s})$ means that intermediates are more costly when shipped from abroad. Therefore, South firms operating in the upstream need to have low enough wages to make production sharing attractive to the North.

Given equation (5), intermediates' price at each stage can be expressed as a function of wages $w_{N}, w_{S}$ and cutoff stage $\tilde{s}$ :

$$
\begin{gathered}
P(s)=\left(e^{\lambda_{S} s}-1\right)\left(\frac{w_{S}}{\lambda_{S}}\right) \quad \text { for } s \leq \tilde{s} \\
P(s)=e^{\lambda_{N}(s-\tilde{s})} \tau P(\tilde{s})+\left(e^{\lambda_{N}(s-\tilde{s})}-1\right)\left(\frac{w_{N}}{\lambda_{N}}\right) \quad \text { for } \tilde{s}<s \leq 1
\end{gathered}
$$

Equation (10) suggests that for the South, the price of intermediates is positively related to the domestic wage and efficiency (the inverse of $\lambda$ ). It is also positively correlated with the complexity level of its intermediates, which is implied by the value of $s$-higher $s$ represents a later stage of the production process, indicating a larger number of preceding stages needed to produce it. Equation (11) illustrates that the price of intermediates produced in the North depends not only on its own factor price, efficiency level and the relative stage of the intermediate good, but also on the trade costs and the price of upstream inputs imported from 
the South. Due to the sequential nature of the production process, a change in the price of South intermediates not only affects the price charged by its direct customers, but also the prices of all downstream firms along the supply chain.

Having characterized the possible equilibria, I now turn to analyzing how the global unbundling shapes the interdependence between North and South, and the impact of a fall in trade costs on countries' production structures, wages, and international inequality.

\subsection{Consequences of Global Unbundling}

In this subsection, I focus on the following thought experiment: suppose initially there is no production sharing between North and South due to high trade costs in intermediates. When trade costs decrease gradually, what will be the implication for their specialization patterns, wages, inequality and the allocation of workers and stages?

To answer this question, assume that the North is "developed" before global unbundling. That is, I start from the separate-production equilibrium where the South produces using the traditional technology while the North has already built its modern sector. In this equilibrium, the South economy can be characterized by equations (3) and (4) while the North economy can be characterized by equations (6)-(8). In particular, wages in the two countries are as follows:

$$
\begin{gathered}
w_{S}=1 / a \\
w_{N}=\frac{\lambda_{N}}{e^{\lambda_{N}}-1}
\end{gathered}
$$

As $a>\frac{\lambda_{N}}{e^{\lambda_{N-1}}}$, there is a wage gap between North and South. Obviously, if trade costs become low enough, South firms will find it profitable to produce intermediates at home and serve downstream firms in the North. Note that this change cannot start from an "interior" stage, since then South firms would need to import inputs from upstream North firms and serve the North with their own intermediates. Since each stage is atomic, benefits from having a lower wage would be outweighed by the cross-border efficiency loss. Therefore, production unbundling can only start from the bottom of the supply chain. Given this, it is easy to compute the cut-off $\tau$ below which production unbundling begins. When production sharing happens, prices and wages must satisfy equations (9)-(11). Together with the price boundary and labor market clearing conditions, the next lemma is immediate: 
Lemma 2-3. There exists a unique cut-off $\tau_{1}\left(\tau_{1}=\frac{\lambda_{N}}{e^{\lambda_{N}-1}} \frac{1}{a}>1\right)$ below which the North starts outsourcing upstream stages to the South. Before the South is fully specialized, the equilibrium condition is characterized by equations (9),(12), and (14)-(17):

$$
\begin{gathered}
1-\tilde{s}=-\frac{1}{\lambda_{N}} \ln \left(1-\frac{\lambda_{N} L_{N}}{Q_{1} / \tau}\right) \\
Q_{1}=e^{-\lambda_{S} \tilde{s}} Q_{0} \\
P(\tilde{s})=\left(e^{\lambda_{S} \tilde{s}}-1\right)\left(\frac{w_{S}}{\lambda_{S}}\right) \\
P(1)=e^{\lambda_{N}(1-\tilde{s})} \tau P(\tilde{s})+\left(e^{\lambda_{N}(1-\tilde{s})}-1\right)\left(\frac{w_{N}}{\lambda_{N}}\right)=1
\end{gathered}
$$

with regularity condition

$$
L_{S}^{M}=\frac{Q_{0}\left(1-e^{-\lambda_{S} \tilde{s}}\right)}{\lambda_{S}} \leq L_{S}
$$

where $L_{S}^{M}$ denotes the amount of labor employed in the modern sector in country $S$. Here, $Q_{1}$ denotes the cutoff stage output, and $Q_{0}$ denotes the input at initial stage zero. As there is only one value chain, I drop country subscripts from price and quantity for simplicity.

With seven unknowns, $\tilde{s}, w_{N}, w_{S}, p(\tilde{s}), Q_{1}, Q_{0}$ and $L_{S}^{M}$, and seven equations, the system is exactly identified. Equations (14) and (15) are derived from equations (1) and (2) and the market clearing conditions of the North. Equation (15) reflects the fact that intermediate goods get lost along stages. Equation (14) suggests that the extent of stages that North occupies depends positively on the size of the country and negatively on the number of intermediates imported from the South that need to be processed. Lemma 2-3 implies that at the beginning of production unbundling, since trade costs are still high, the stage outsourced from the North to the South cannot absorb all the labor force in the South, and thus the traditional sector co-exists with the modern sector in the South.

In the Appendix, I show that $L_{S}^{M}$ is a decreasing function of $\tau$. Therefore, as $\tau$ decreases, the amount of labor employed in the modern sector increases. Hence there exists another cutoff value of trade costs below which country $S$ will fully specialize. Similar to Lemma 2-3, in the fully specialized equilibrium, wage and price equations (9)-(11), the price boundary and labor market clearing conditions must be satisfied. This gives us Lemma 2-4: 
Lemma 2-4. There exists a unique cut-off $\tau_{2}<\tau_{1}$, below which the traditional sector is fully absorbed in the South. After the South is fully specialized, the equilibrium condition is characterized by equations (9), (14)-(17), and (19):

$$
\tilde{s}=-\frac{1}{\lambda_{S}} \ln \left(1-\frac{\lambda_{S} L_{S}}{Q_{0}}\right)
$$

Equations characterizing the complete production-sharing equilibrium are similar to those of the incomplete production-sharing equilibrium in Lemma 2-3, with the exception of equation (12) now being replaced by the labour market clearing condition of the South (equation (19)). There is no explicit analytical expression for $\tau_{2}$, but by letting $L_{S}^{M}=L_{S}$, and using equations (14), (15), and (16) to write $Q_{0}, Q_{1}$ and $P(\tilde{s})$ as functions of $e^{\tilde{s}}$, and substituting into (18), we obtain:

$$
\tau_{2}=\frac{L_{S}}{L_{N}} \frac{\lambda_{S}}{\lambda_{N}} \frac{1-e^{-\lambda_{N}(1-\tilde{S})}}{e^{\lambda_{S} \tilde{s}}-1}
$$

Note that $\tau_{2}$ is negatively related to the relative size of country $S$. Suppose trade costs drop steadily-this implies that bigger developing countries will require more time to fully specialize.

An important reason as to why the second unbundling attracted a lot of attention among policy makers and economists is that many developing countries that joined supply chains in the 1980s also achieved sustainable economic growth. China, Thailand and India, to name a few, have moved up along the value chain steadily and experienced great welfare improvements. I now consider, given the existence of production sharing (incomplete or complete), how a drop in trade costs shapes wages, production structure, and income inequality across nations.

Proposition 1-1. At incomplete specialization, as trade costs $\tau$ go down, South wage stays the same while North wage increases. The traditional sector in South shrinks and the modern sector expands. South moves up along the supply chain, and the total output of final good increases.

I call South moves up the value chain if the cutoff stage $\tilde{s}$ increases. The broad intuition behind Proposition 1-1 is simple. As South is incompletely specialized, wage is pinned down by the traditional sector and remains unchanged when trade costs go down. However, as trade gets less costly, the advantage of having cheaper labor enables South firms to occupy relatively higher stages of production, so the cut-off price $p(\tilde{s})$ rises. According to equation (9), this also lifts the Northern wage. From a welfare perspective, a decrease in trade costs 
means less efficiency loss, and hence higher world output. Since $w_{S} L_{S}+w_{N} L_{N}=Q$, and the real wage of the South is unchanged, it must be that the real wage in the North increases, which means an increase in wage inequality. Furthermore, as the South operates in a larger share of stages than before, it demands more labor in the modern sector. Therefore, workers move from the traditional sector to the modern sector in the South as trade costs fall.

Proposition 1-2. At complete specialization, as trade costs $\tau$ go down, both countries' real wages increase, and wage inequality decreases. The South moves up along the supply chain, and the total output of final good increases.

The intuition behind Proposition 1-2 is as follows. A decrease in trade costs leads to efficiency gains - therefore the South occupies more stages of the supply chain than before and the world output increases. Changes in the pattern of vertical specialization translate naturally into a change of real wages. After the South fully specializes, the increased demand for South's intermediate goods leads to an increase in South wages. Both countries benefit from decreased trade costs as real wages increase. The rationale behind the changes in the world income distribution is more subtle. Equation (15) shows that a decrease in $\tau$ means a decrease in wage inequality. However, there is an additional indirect effect: the decrease in $\tau$ leads to an increase in $p(\tilde{s})$, which implies higher wage inequality. These two forces work in the opposite direction and the decrease in wage inequality tells us that the direct effect from $\tau$ dominates.

The response of vertical specialization patterns to trade cost changes is illustrated in the left panel of Figure 1. The right panel of Figure 1 explains the response of wages in each nation, and the North-South wage gap defined as $\left(w_{N}-w_{S}\right) / w_{S}$. From right to left, the coloured areas indicate the range of $\tau$ corresponding to separate production, incomplete specialization and complete specialization, respectively.

Proposition 1-1 and 1-2 offer a picture of how the interdependence between North and South changes as trade frictions in intermediates gradually fall. The process is nonlinear: when trade costs are very high, there is no production sharing and a small decrease in $\tau$ does not change this pattern. As trade costs go down sufficiently, countries first switch to incomplete specialization, and later to complete specialization as costs continue to decrease. In the beginning of the unbundling, although the range of intermediates that South produces gets larger, its domestic wage does not rise because of the abundant labor supply from the traditional sector; thus, the wage gap between North and South widens. As global unbundling gets deeper, the modern sector absorbs all the labor from the traditional sector in the South, and the real wage starts rising. In this period, a steady decrease in trade costs drives up real wages in both countries, and the income gap between North and South starts narrowing. 

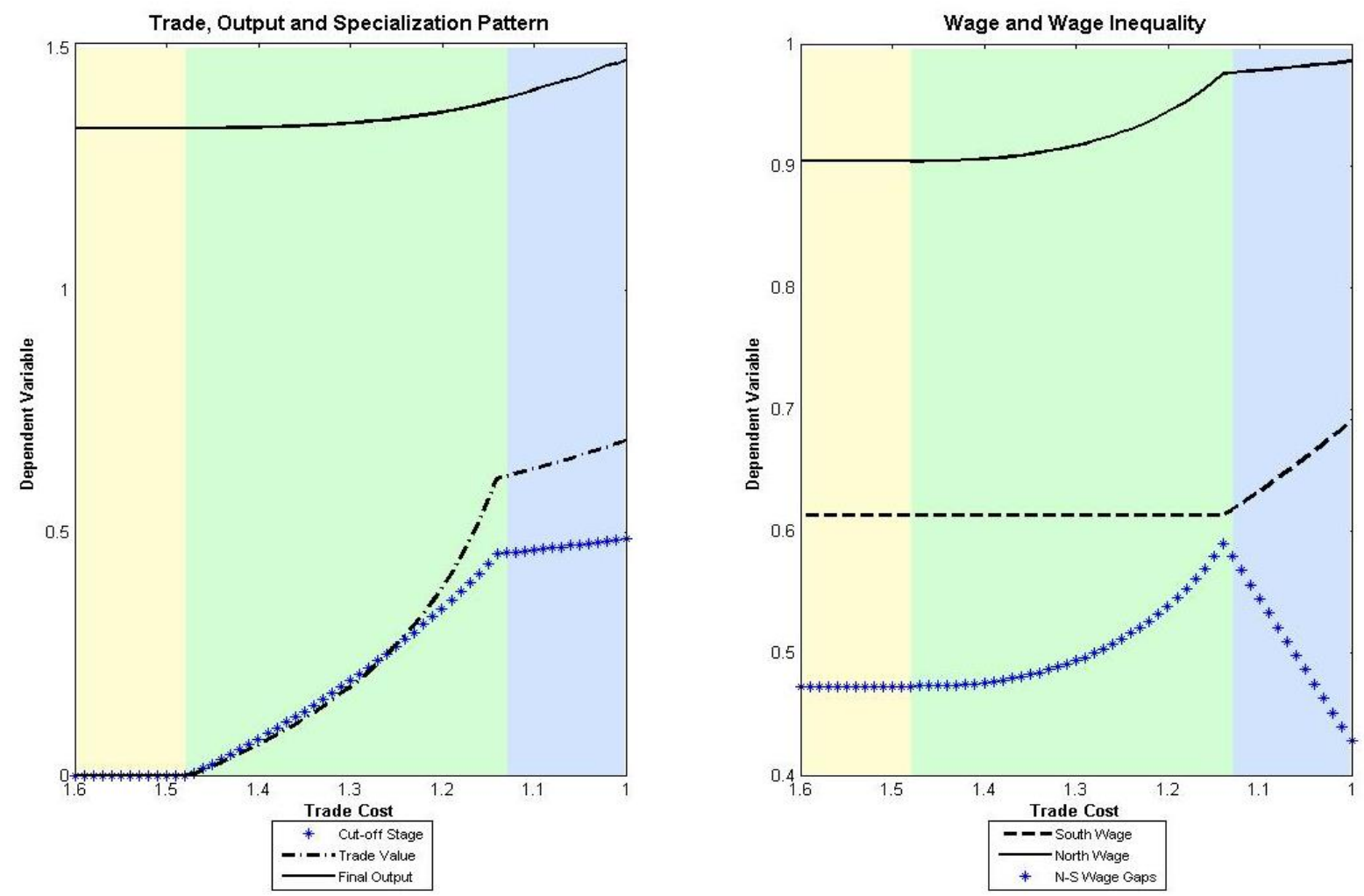

Figure 1. Consequences of decreases in trade costs

\subsection{Discussions}

Driven by the ICT revolution and other technological progress, the "international trade glue" began to loosen in the 1980s. Motivated by the wage differential between North and South, production stages that used to be performed in close proximity began to be offshored to different countries - this continued as trade costs kept falling. (Baldwin, 2011) coined this "the global second unbundling". I have provided a simple model that captures this mechanism. Before turning to multi-nation extensions, I briefly discuss the model's performance in matching the empirical stylized facts and several novel insights it provides.

\section{Fragmentation, trade frictions and terms of trade effects}

The analysis provided in section 2.3 matches several stylized facts. Firstly, since a drop in trade costs implies that the South moves up along the value chain, we should observe an increased complexity in developing countries' production and exports. This has been documented by Thornton and Thompson (2001), Levitt et al. (2013) and Malerba (1992). Secondly, as there is additional value-added in each stage, the value of supply-chain trade should increase steadily as trade costs decline, as documented by Johnson and Noguera (2012a). The model also generates a non-linear wage response to trade cost changes that matches the anecdotal evidence on the evolution of developing country wages. 
Policy papers like the recent OECD reports argue that trade frictions matter more in a world with GVCs (OECD (2013)), as intermediates may cross borders several times before a final good is made. My model provides additional insight into why trade costs matter more for supply-chain trade. The value-added nature of sequential production implies that unit values increase along the supply chain, and as communication costs go down, trade frictions become more costly as the per-unit value of the cut-off intermediate good increases. This means that supply chain trade becomes more sensitive to trade frictions as production sharing deepens.

The model described above implies that in the second episode of global unbundling, moving up along the value chain in the South is associated with real wage increases. This is probably one of the key reasons as to why GVCs attract considerable attention among policy makers and are considered a way to raise developing countries out of poverty. Notice that the second cut-off tariff $\tau_{2}$, is negatively related to the relative size of the South. That is, the smaller the South relative to the North, the easier it is to gain from trade cost drops. This is consistent with the classical Ricardian trade theory that small countries gain more from free trade due to terms of trade effects.

\section{Transformed industrialization}

The interdependence of firms in the modern sector is reminiscent of the "Big Push" literature emphasizing the importance of coordinated development. ${ }^{\mathrm{k}}$ However, as shown in the model, when $a<\frac{\lambda_{S}}{e^{\lambda} S-1}$, even a government-led economic development plan will not lead the South to prosperity - for the South, modern industry with separate-production is not a stable equilibrium, and it offers lower wages compared to the traditional equilibrium. This provides a complementary explanation for the failure of the first and second generation "Big Ideas" (Lindauer and Pritchett, 2002), and the mixed evidence for the success of "Big Push" development as documented by Bjorvatn and Coniglio (2012), Easterly (2006), Kline and Moretti (2011), Magruder (2013), among others. Admittedly stylized, the broad message of the results is still important: when a country's production is not efficient-either due to an inefficient legal system, poor public infrastructure or else, organizing the production process in a modern way can be very costly. ${ }^{1}$ In that case, "Big Push" industry strategies will fail to free the South from its poverty trap.

On the other hand, the second unbundling can transform incompetent developing nations into world-class exporters by enabling them to specialize in a certain part of the production process. Before the second unbundling, if the South wanted to develop a globally competitive modern economy, it had to develop a broad and deep industrial base, probably also to

\footnotetext{
${ }^{\mathrm{k}}$ See for instance Murphy, et al. (1989). The difference is that in my model the interdependence also exhibits a vertical structure.

${ }^{1}$ See for instance Chang, et al (2009) for empirical evidence.
} 
improve its efficiency for a wide range of production processes. Such tasks are arduous and only a few countries have succeeded historically (e.g. Japan and South Korea). Nevertheless, after the second unbundling, developing countries found an alternative way to modernize, namely by producing intermediate goods for the advanced North. In my model, the gains from trade come from better specialization, which is a recurrence of the classical gains from the Ricardian trade in a sequential-production setting. Decreasing trade costs in intermediates offers new development and industrialization opportunities for the South.

Nevertheless, theory presented here should be considered as a complement rather than a substitute for the coordinated-development theory. My model characterizes a new industrialization possibility which is comparatively easier to achieve. The rising Asian countries like China, Thailand and Vietnam seem to have followed this path. However, as implied by the model, without a catch-up in productivity, the South will remain specialized at the bottom of the value chain and earn lower wages. If the South wants to increase its productivity and produce more complicated intermediates, a coordinated improvement of efficiency across production stages still matters. A formal discussion of technology upgrading via joining a value chain is however beyond the scope of this paper.

\section{Sequential Production with Many Countries and Bilateral Trade Frictions}

Global production is increasingly sliced, spanning multiple countries from different continents. With more countries vertically specialized and participating in the GVCs, the global production and trade patterns become more complex and asymmetric. A setting with more than two countries is clearly needed to capture such complexity, which is what I aim to achieve in this section. I start with a general case where multiple nations feature different productivity levels and bilateral trade frictions to analyse the production sharing and joining patterns; then I focus on a one-North, multiple-South setting for insights on welfare interdependence across countries.

\subsection{Set-ups and Definitions}

There are $\mathrm{N}$ Countries, $\mathbf{C}=\left\{\mathrm{C}_{1}, \mathrm{C}_{2}, \ldots, \mathrm{C}_{\mathrm{N}}\right\}$, each with its own technology level, $\lambda_{\mathrm{C}}$. Without loss of generality, countries are ordered such that $\lambda_{C}$ decreases in C. Bilateral trade cost between country $i$ and $j$ is denoted by $\tau_{\mathrm{C}_{\mathrm{i}} \mathrm{C}_{\mathrm{j}}}$. Triangular inequality is assumed to hold

throughout the rest of the paper, i.e. $\tau_{\mathrm{C}_{i} \mathrm{C}_{n}} \leq \tau_{\mathrm{C}_{\mathrm{i}} \mathrm{C}_{\mathrm{n}}} * \tau_{\mathrm{C}_{n} \mathrm{C}_{\mathrm{j}}}$ for $\forall \mathrm{C}_{\mathrm{i}}, \mathrm{C}_{\mathrm{j}}, \mathrm{C}_{\mathrm{n}} \in \mathbf{C}$. All remaining assumptions are the same as in section 2 .

With the presence of trade frictions in a multiple country setting, the international production sharing is more a "supply-chain network" with multiple value chains intertwined 
with each other-it is possible that one country participates in multiple value chains at the same time. Given such complexity, it is useful to first introduce some formal definitions to describe the global production environment, as well as to update some definitions on, for instance, vertical-specialization patterns and income distributions to fit the multi-country setting.

I start by formally defining "value chain" and "supply-chain networks"”:

Definition 1. For any final good $g$, the allocation of stages across countries is characterized by the function $C_{g}: S \rightarrow \mathbf{C}$.

According to definition $1, C_{g}$ maps the production stages of good $g$ to countries participating in its production process. For instance, if country $C_{1}$ participated in its production at stage $s$, then $C_{g}(s)=C_{1}$. ${ }^{\mathrm{n}}$ This offers a complete picture of the production process for each good. The range of function $C_{g}(s)$ is defined as $\boldsymbol{C}^{g}$.

Although final goods are homogenous to consumers, they can be "differentiated" by how they were produced to facilitate the definition of a value chain. Intuitively, if two final goods have each stage produced in exactly the same countries, they are considered as "the same good." Formally this can be presented as: for final goods $g$ and $f$, if $C_{g}(s)=C_{f}(s)$ for $\forall s \in$ $\boldsymbol{S}$, then $g=f$.

Definition 2. $C^{V}=\left\{C_{1}, C_{2}, \ldots C_{k}\right\}$ constitutes a value chain $V$ if there exists a final good $g$, the range of whose stage-allocation function, $C_{g}(\boldsymbol{S})$, equals $\boldsymbol{C}^{V}$.

According to definition 2, if there exists a good $g$, whose stages are allocated to and only to countries $C_{1}, C_{2}, \ldots C_{k}$, I say those countries constitute a value chain, denoted V. For instance, if there exists a good $g$ that has stages $(0,0.4]$ produced in $C_{i}$ and stages $(0.4,1]$ produced in $C_{j}$, then $C_{i}$ and $C_{\mathrm{j}}$ constitute a value chain. One might notice that such characterization allows the possibility of different final goods to share the same value chain. For instance, it is possible that good $g$ has stages $(0,0.4]$ produced in $C_{i}$ and stages $(0.4,1]$ produced in $C_{j}$, while good $f$ has stages $(0,0.6]$ produced in $C_{i}$ and stages $(0.6,1]$ produced in $C_{j}$. The definition of value chain does not allow distinguishing between the two production processes, as both boil down to $\boldsymbol{C}^{V}=\left\{C_{i}, C_{j}\right\}$. However, it turns out that in equilibrium, one value chain corresponds exclusively to the production process of one good (i.e. the production

\footnotetext{
m In the paper I use "value chain" and "supply chain" interchangeably. Here the distinction focuses on "chain" and "networks." In the two-country setting, the value chain is the supply-chain network; while in the multi-country setting, a value chain is part of a supply-chain network.

${ }^{\mathrm{n}}$ With a slight abuse of notation, I put both the indicator of countries, $C_{i}$, and the indicator of a particular good, $g$, at the subscript. The meaning should be clear given the context.
} 
structures described above cannot coexist). This is elaborated in the proofs for Lemma 3-1, which I report in the Appendix ${ }^{\circ}$.

Definition 3. $\boldsymbol{C}^{S}=\left\{C_{1}, C_{2}, \ldots C_{k}\right\}$ constitutes a supply-chain network $S$ if there is no intermediates trade between $C_{i}, C_{j}$ for $\forall C_{i} \in \boldsymbol{C}^{\S}, C_{j} \in \boldsymbol{C} / \boldsymbol{C}^{\S}$; and there is no partition of $\boldsymbol{C}^{\S}$ such that $\boldsymbol{C}^{\prime}, \boldsymbol{C}^{\S} / \boldsymbol{C}^{\prime}$ satisfies that there is no intermediates trade between $C_{i}, C_{j}$ for $\forall \mathrm{C}_{\mathrm{i}} \in \boldsymbol{C}^{\prime}$, $\mathrm{C}_{\mathrm{j}} \in \boldsymbol{C}^{\mathrm{S}} / \boldsymbol{C}^{\prime}$

According to definition 3, countries that have direct or indirect production linkages are considered in the same network. If two countries are in the same value chain, then they must be in the same network, but not necessarily the other way around.

Also we say there is direct production sharing between countries $C_{i}$ and $C_{j}$ if the production stages that they participate in follow each other's. Countries in the same supplychain network may not have any production sharing.

The definitions of "moving up a value chain" and "increase in wage inequality" follows Costinot, Vogel and Wang (2013) :

Definition 4. Suppose $\boldsymbol{C}^{V}=\left\{C_{1}, C_{2}, \ldots C_{k}\right\}$ constitutes a value chain. Country $C$ is moving up if both its importing and exporting cutoff stages inside the value chain increase weakly.

Definition 5. Suppose $\boldsymbol{C}^{\boldsymbol{V}}=\left\{C_{1}, C_{2}, \ldots C_{k}\right\}$ constitutes a value chain. Wage inequality increases if among a given group of adjacent countries, $C_{i+1} / C_{i}$ increases.

\subsection{The General Specialization and Joining Pattern}

When countries $\boldsymbol{C}^{V}=\left\{C_{1}, C_{2}, \ldots C_{k}\right\}$ participating in the same value chain are ordered by their technology level such that $\lambda_{C_{i}} \leq \lambda_{C_{i-1}}$ for $\forall i=2, \ldots, k$, the specialized pattern discussed in section 2 still holds weakly. This is summarized in the following lemma.

Lemma 3-1. Within any value chain $V$, the allocation of stages to countries $C^{V}: \boldsymbol{S} \rightarrow \boldsymbol{C}^{\boldsymbol{V}}$ is an increasing function of $s$.

According to Lemma 3-1, within any value chain, the specialization pattern is always such that more productive countries produce and export at the later stages of production. The formal proofs can be found in the Appendix. Briefly, I proceed with the proposition in two steps. First, as proved for Lemma 2-2, if there is direct production sharing between two countries, the intermediates must flow from the less productive to the more productive

\footnotetext{
${ }^{\circ}$ As final goods and value chains are mapped one to one, allocating stages across countries for final good $g$ is equivalent to allocating stages for the value chain $\mathrm{V}$ it corresponds to. Hence in the following sections I use notations $\mathrm{C}^{\mathrm{V}}: \mathbf{S} \rightarrow \mathbf{C}$ and $\mathrm{C}_{\mathrm{g}}: \mathbf{S} \rightarrow \mathbf{C}$ interchangeably.
} 
country. In fact, this holds for any two countries with direct production sharing. Second, I prove that one value chain corresponds exclusively to the production process of one good. Since only one country is involved in producing the good at each stage, the ranking of countries is preserved along the whole value chain.

Lemma 3-2. There is no production sharing between any $C_{i}, C_{j}$ with $\lambda_{C_{i}}=\lambda_{C_{j}}$ in equilibrium if trade friction exists.

Lemma 3-2 follows directly from Lemma 3-1 and the triangular inequality. Lemma 3-1 explains that if two countries with the same technology are in the value chain, they must be ordered next to each other; therefore, direct production sharing exists between $C_{i}$ and $C_{j}$. As $\lambda_{C_{i}}=\lambda_{C_{j}}$, direct production sharing could happen if and only if $w_{i}=w_{j} \tau_{i j}{ }^{\mathrm{p}}$. However, with $w_{i}=w_{j} \tau_{i j}$, firms in country $i$ are indifferent to using intermediates produced domestically or from country $j$ at each stage country $i$ occupies. Therefore, the stage country $i$ occupies will also be occupied by country $j$. Denote the highest stage country $i$ occupies as $\bar{s}$. If $\bar{s}=1$ then final goods produced in country $j$ will be cheaper, which contradicts the fact that final goods are freely traded and price equals across nations; if $\bar{s}<1$, then by the triangular inequality, the downstream consumer of country $i$ will strictly prefer to source goods from country $j$ instead. Hence Lemma 3-2 is proved by contradiction.

Lemma 3-3. Countries that start without an industry base can only join a value chain via stage zero. Countries that already have an industry base join value chain V via the stage it has the highest trade-friction-adjusted price gap with; formally, denote the joining country as $C_{i}$ and its joining stage as $s^{\Delta}, s^{\Delta}=\left\{s \mid \operatorname{argmax}_{s \in S}\left[\max \left(\frac{P_{C_{i}}(s)}{{ }_{C_{C_{j}}(s) \tau_{C_{i}} C_{j}}}, \frac{{ }^{P} C_{C_{j}}(s)}{{ }_{C_{i}}(s) \tau_{C_{i}} C_{j}}\right)\right] ; C^{V}(s)=C_{j} ; Q_{C_{i}}(s)>0\right\}$.

The first part of Lemma 3-3 explains that the country that starts from a "poverty trap" can only join a value chain from its bottom. Denote the country that only has a traditional industry as country $k$; the proof formally proceeds in two steps. First, similar to Lemma 2-3, for modern firms in country $k$, shipping intermediates from country $i$, processing and then shipping them back to $i$ is more costly than for any firm that produces within country $i$ at the same stage. Thus, production unbundling cannot happen at any stage in which the supply and demand linkages are domestic. Second, one can prove that unbundling cannot happen at a cutoff stage either due to the triangular inequality. As a result, despite the potential technology level $\lambda_{k}$, country $k$ can only join a value chain from the bottom. The second part of Lemma 3-3 is straightforward: as long as the price gap between two countries exceeds their bilateral trade friction, downstream firms of one country will find it more profitable to import

\footnotetext{
${ }^{\mathrm{p}}$ Without loss of generality, I assume country $j$ is preceding country $i$ in ranking.
} 
from the other. This proposition sheds light on the importance of domestic industry linkages in facilitating the joining.

This subsection provided several important insights on GVCs. First, despite the complexity of global supply-chain networks, within each value chain, the vertical specialization pattern still holds: countries with more advanced technology occupy the downstream of the value chain while countries with less advanced technology occupy the upstream. Second, although countries' positions inside a value chain depend only on their technology efficiency, whether they will be inside or outside of the chain depends crucially on their trade frictions with other countries already in the chain. In addition, given the wage level, it is much easier for a country to join a supply chain if it already has an industry base.

\subsection{Two Thought Experiments}

Since the 1980s, trade costs have decreased significantly, mainly owing to technological progress. Rapid advances in ICT greatly reduced communication and transport costs. Cheaper and more reliable telecommunication facilities made coordinating complex activities across borders much easier and timely; advancement in computer software made the development of international multimodal transport system and "door-to-door" transportation possible, which greatly facilitated the movement of goods in supply-chain networks. This section discusses potential implications of such changes for developing countries. The questions of interest are how a South nation joins GVCs, and what is its impact on the welfare of other countries?. I focus on a one-North, multiple-South setting to emphasize the key insights of the model.

\section{Identical South and the Hub-and-Spoke Economy}

I restrict my attention to an economy with one North N, and K South with identical technology $\lambda_{\mathrm{S}}$. Hence the country set now equals $\boldsymbol{C}=\left\{N, S_{1}, S_{2} \ldots . S_{K}\right\}$. As in section 3.2, I impose no assumptions on bilateral trade frictions except the triangular inequality. A decrease in global trade costs is defined as a change in bilateral trade frictions from $\tau_{C_{i} C_{j}}$ to $\theta \tau_{C_{i} C_{j}}$ for all $C_{i}, C_{j} \in \boldsymbol{C}$, with $\theta<1$.

Equalizing productivity across the South yields a relatively simple specialization pattern. According to Lemma 3-2, there will be no production sharing between nations with the same productivity. Therefore the global production network must be of a hub-and-spoke structure, with headquarter economy, the North, operating in downstream stages while factory economies, the South countries inside the supply-chain network, operating in upstream stages and providing intermediates to the North independently.

Moreover, as shown in the proof of Lemma 2-2 in the Appendix, if the production sharing cut-off between North and a South is $\tilde{s}$, then North will not operate in stages lower 
than $\tilde{s}$. This means that the cutoff stages between North and South are the same for every South country. The next proposition is therefore immediate:

Proposition 2-1. If international production sharing exists, it must be that there exists a stage $\tilde{s} \in(0,1)$ such that $Q_{S}(s)>0$ if and only if $s \in(0, \tilde{s}]$ for all joined South, and $Q_{N}(s)>0$ if and only if $s \in(\tilde{s}, 1]$.

Next I characterize the joining pattern of South nations. Again I assume initially that no South country is industrialized. For convenience, I denote the $j$-th South that joined the supply chain as $\mathrm{S}_{\mathrm{j}}^{I}$, with superscript $I$ indicating "Insiders." Obviously, production sharing starts between the North and South pair that has the lowest bilateral trade frictions. Lemma 3-3 explains that non-industrialized countries can only join value chains from the bottom; Proposition 2-1 implies that every joining South has firms that produce at the very bottom stage; therefore, a South $S_{i}$ always joins the production network via exporting intermediates at the very beginning stage to the insider-South that has the highest proximity-adjusted wagegap with itself, which is $\operatorname{argmax}_{S_{k}^{I} \in\left\{S_{1}^{I}, \ldots, S_{j-1}^{I}\right\}} w_{S_{k}^{I}} / \tau_{S_{k}^{I} S_{i}}$. This is intuitive, as firms from inside-South only find it optimal to import intermediates from an outside-South when: (1) intermediates are cheaper, and (2) trade frictions are low. With some algebra one can show that it is equivalent to $\min _{S_{k}^{I} \in\left\{S_{1}^{I}, \ldots, S_{j-1}^{I}\right\}} \tau_{S_{k}^{I} S_{i}} * \tau_{N S_{k}^{I}}$. Denote $S_{k}^{I}$ that minimize $\tau_{S_{k}^{I} S_{i}} * \tau_{N S_{k}^{I}}$ as $\mathrm{S}^{I}\left[\mathrm{~S}_{\mathrm{i}}\right]$, then the following proposition is immediate:

Proposition 2-2. As trade frictions fall globally, the joining pattern of South is such that $\mathrm{S}_{\mathrm{j}}^{I}=\operatorname{argmin}_{S_{i} \in C} \tau_{N S_{i}}$ for $j=1 ; \mathrm{S}_{\mathrm{j}}^{I}=\operatorname{argmin}_{S_{i} \in C /\left\{S_{1}^{I}, \ldots, S_{j-1}^{I}\right\}} \tau_{\mathrm{S}^{I}\left[\mathrm{~S}_{\mathrm{i}}\right], S_{i}} * \tau_{N, \mathrm{~S}^{I}\left[\mathrm{~S}_{\mathrm{i}}\right]}$, for $\mathrm{j} \geq 2$.

Proposition 2-2 explains that the South with the lowest trade cost with the North will join the supply chain first. Since $\tau$ indicates the proximity between countries, Proposition 2-2 says that the joining sequence of other South countries depends on their "indirect proximity" with the North. Interestingly, except for the first joined South, proximities between the outside South countries and the North plays no role in deciding which South joins first. Proximity with joined South matters for successful joining, though in equilibrium there is no direct trade between joined South nations. This implies that even when each South exports intermediates to the North independently and does not interact with each other in equilibrium, factor economies are likely to be regionally clustered.

Proposition 2-3. The entry of a new South increases the North's real wage but decreases the other insider-South's real wages. All South countries move up the value chain. 
The joining of a new South means increased supply of intermediates for the North, which lowers the price of intermediates and hence wages. The rationale behind changes in cutoff stages is also straightforward: the joining of new South can be thought of as an increase in the size of an aggregated South. With the labor-market-clearing conditions for all nations, this implies that the North will specialize in fewer stages. Proposition 2-3 is essential as it implies that the number of stages a country occupies does not necessarily reflect its welfare level—moving up a value chain can be associated with welfare losses as well.

Proposition 2-4. Conditional on no new entry, if there exists an incompletely specialized South, a decrease in trade costs leads North wages to increase but has no effect on South wages. The North-South wage inequality broadens. If all countries are completely specialized, a decrease in trade costs leads to a real wage increase for all countries inside the supply chain, and the North-South wage inequality narrows. In both cases, South countries move up along the supply chain, and the total output of final goods increases.

As proved in the Appendix, all joined South countries can be thought of as an aggregated South--the effectively the sum of trade-friction-weighted sizes of each joined South country. Therefore the comparative analysis is exactly the same as the two-country case discussed in section 2. The logic behind the changes in the pattern of vertical specialization and wages is akin to that of Propositions 1-1 and 1-2. However, introducing many South nations sheds light on the third-country effects. Given the hub-and-spoke production-sharing structure, trade in intermediates does not occur between two South nations, yet their wage levels and stages occupied are closely related ${ }^{\mathrm{q}}$.

The country dynamics associated with a decline in global trade frictions are illustrated in Figure 2. Henceforth the $\mathrm{x}$-axis refers to $\theta$. The left panel explains the change in cutoff stages, trade values and the world GDP, while the right panel illustrates the response of wages and the free-on-board (FOB) price. From left to right, the colored areas indicate the range of trade frictions that corresponds respectively to (1) separate production, (2) the-first-South-joining and incompletely-specialized production, (3) completely-specialized production, (4) thesecond-South-join and incompletely-specialized production, and (5) the production equilibrium that both South completely specialized. As trade costs fall and South countries join the value chain, total output of final goods, trade in intermediates and North wages increase. Note that the first-joined-South's wages increase initially, and then decrease when the second South joins. Following the second South's complete specialization, both South wages increase.

\footnotetext{
${ }^{\mathrm{q}}$ The stages occupied are identical across all joined South nations; the wage ratio between two South nations is identical to the difference between their trade frictions with the North, i.e. $\frac{w_{i}}{w_{j}}=\frac{\tau_{S_{j} N}}{\tau_{S_{i} N}}$.
} 

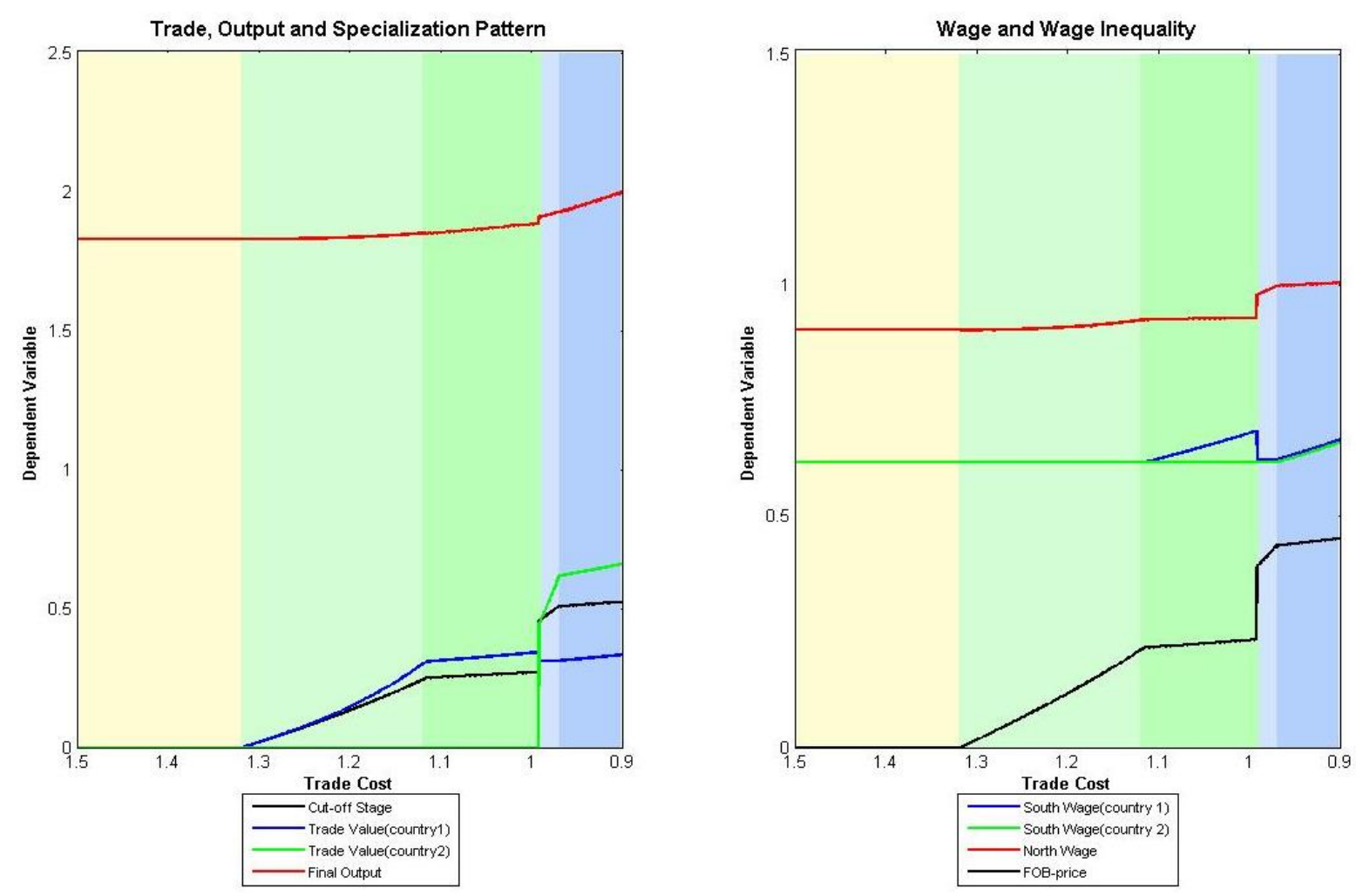

Figure 2. Consequences of decreases in trade costs (hub-and-spoke)

\section{Learning by Doing and the Flying Geese}

In previous analyses, I assumed that all South nations have the same technology $\lambda_{S}$, which is fixed over time. Another possibility is that South's failure rates decrease as it accumulates production experience. Such "learning by doing" mechanism has been documented by various empirical studies such as Malerba (1992), Thornton and Thompson (2001) and Levitt, List and Syverson (2013), among others.

To incorporate this into the model, I assume that for a South $S_{i}$, technology $\lambda_{S_{i}}=$ $\alpha\left(t_{i}\right) \lambda_{S}$, where $t_{i}$ indicates how long $S_{i}$ has been in the value chain and $\alpha($.$) is a$ monotonically-decreasing function with range $\alpha(.) \in\left(\frac{\lambda_{N}}{\lambda_{S}}, 1\right)$. This assumption insures that the South who joins the supply chain first will have a lower failure rate, but never as low as the North. I also assume that no two nations have exactly the same trade frictions with a third nation ${ }^{\mathrm{r}}$.

According to Lemma 3-1, in equilibrium, countries will be ordered based on their technology level along a value chain. Since I assume that technology is strictly linked to the time of joining, the latest-joined South will always position at the bottom of a value chain. Since there are no two countries with the same trade frictions with a third nation, joining is

\footnotetext{
${ }^{\mathrm{r}}$ Relaxing this assumption will allow for the possibility of two South nations joining the value chain at the same time, resulting in a mix of hub-and-spoke and sequential structures.
} 
always sequential. Therefore, there is only one value chain in the economy, with the North operating at the very end stages, and South countries being ordered along stages following their joining sequence. Define the set of South countries participating in international production sharing as $\boldsymbol{S}^{I}$, where $\boldsymbol{S}^{I}=\left\{S_{1}^{I} \ldots S_{k}^{I}\right\}$, and order South nations by their joining time (i.e. $S_{1}^{I}$ joined first and $S_{k}^{I}$ joined latest), the next proposition follows:

Proposition 3-1. If international production sharing exists, a sequence of stages, $0<s_{k}<$ $\cdots<s_{1}<s_{N}=1$ can be found such that for all $S \in \boldsymbol{S}^{\boldsymbol{I}}, Q_{S_{i}}(s)>0$ if and only if $s \in$ $\left(s_{S_{i-1}}, s_{S_{i}}\right]$, and $Q_{N}(s)>0$ if and only if $s \in\left(s_{N}, 1\right]$.

According to Proposition 3-1, the only vertical specialization pattern among countries that have joined the supply-chain networks is of a sequential type, with more productive nations producing and exporting in the later stages of production. As productivities of joined South countries are directly related to their time of joining, it also implies that earlier-joined countries occupy relatively later stages of production.

When trade costs decrease, increased factor prices among inside countries provide opportunities for outside South countries thanks to their wage advantage. Since a nonindustrialized South can only join a value chain from its bottom, and the production network constitutes a single value chain, the next proposition is immediate:

Proposition 3-2. As trade frictions fall globally, the joining pattern of South is such that $S_{\mathrm{j}}^{I}=\operatorname{argmin}_{S_{i} \in S} \tau_{N S_{i}}$ for $j=1$; and $S_{\mathrm{j}}^{I}=\operatorname{argmin}_{S_{i} \in S /\left\{S_{1}^{I}, \ldots, S_{j-1}^{I}\right\}} \tau_{S_{j-1}^{I} S_{i}}$ for $\mathrm{j} \geq 2$.

Proposition 3-2 explains that the South with the lowest trade cost with the North will join the supply chain first; the joining sequence of other South nations depends on their proximity with the latest-joined South. Compared to the case of hub-and-spoke economy, sequential specialization provides a stronger version of regional clustering of factory economies, as only the proximity with the latest-joined South matters. If trade frictions are positively correlated with distance, the model implies that the sequentially joined developing nations are geographically close to each other, that is, factory economies are regionally clustered. Furthermore, if a South joins the GVC, its under-developed neighbors may benefit from it. This sequential regional development pattern is reminiscent of Akamatsu's "flying geese of development" (Akamatsu, 1962, Kojima, 2000), which explains that a less-advanced country's economy develops via "entering into an international economic relationship with the advanced countries" (Akamatsu 1962). 

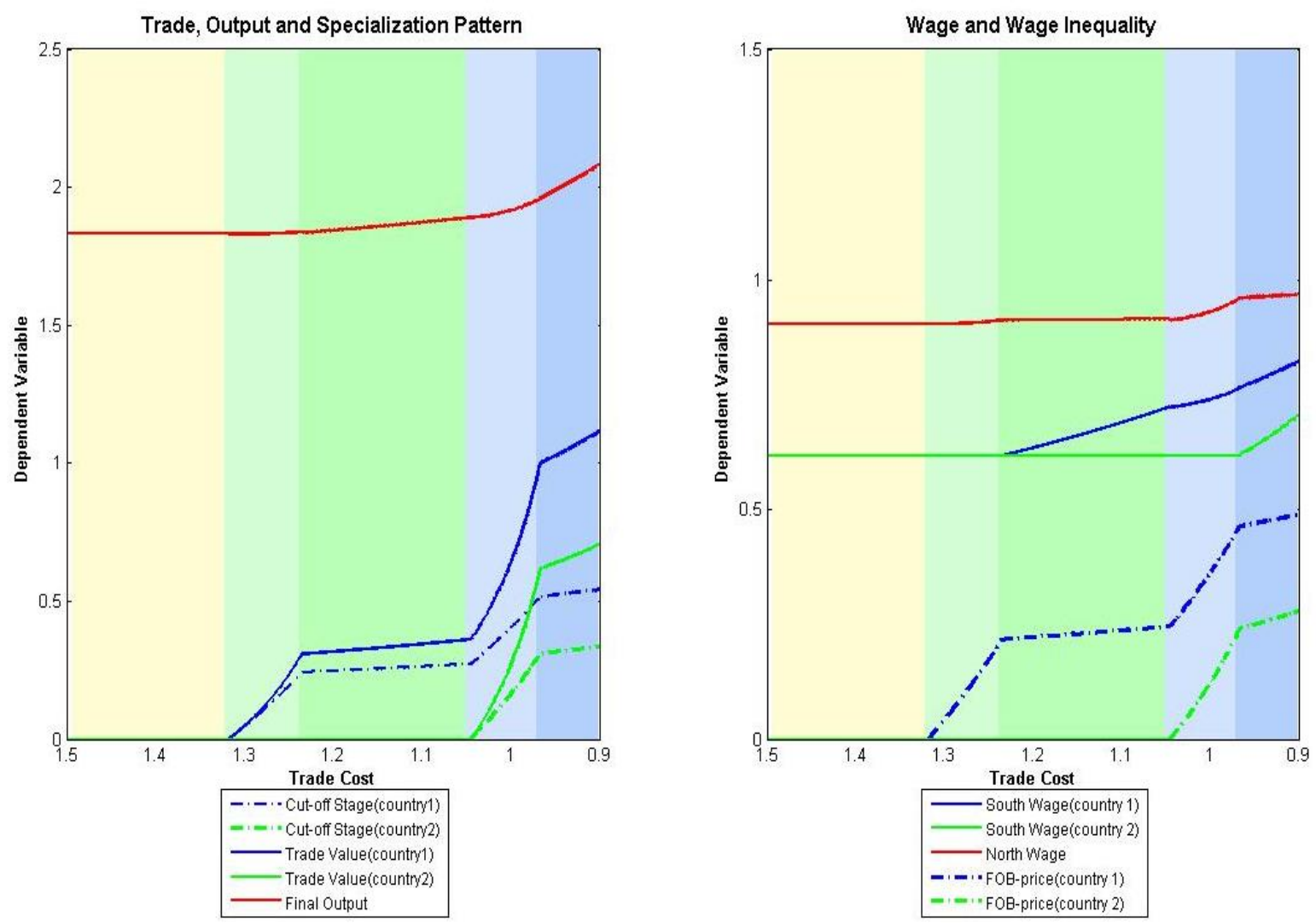

Figure 3.Consequences of decreases in trade costs (flying geese, high tech gap)

When international production sharing exhibits a sequential structure, countries' specialization pattern responds to trade cost changes as in the two-country model, however the evolution of wages across countries is different.

Proposition 2-3. Everything else equal, a decrease in trade costs allows all countries inside the value chain to move up. It also leads to an increase in real wages and a decrease in wage inequality for all countries inside the value chain when they are all fully specialized. When the newly joined South is incompletely specialized, a decrease in trade costs raises the North wage but the effect is ambiguous for the insider South.

The broad intuition behind the changes in the pattern of vertical specialization is akin to what was proved in Proposition 1-2. A fall in trade costs tends to decrease the resource waste that occurs when intermediates are shipped from one country to another. This enables upstream countries to produce fewer intermediates. To make labor markets clear, this decrease in production must be offset by an expansion in stages occupied in those countries. Proceeding by iteration from the bottom of the supply chain, it is simple to show that changes in $N_{c}$ can only occur if all countries move up. When all countries are specialized, a drop in trade costs drives up real wages as final goods become cheaper and trade gets freer. Since trade frictions 
act as a wedge to differentiate wage levels, income inequality decreases in this case as well. The wage response in the incomplete specialization case is more subtle. Recall equation (9) that shows how a country's wage depends on trade frictions, its upstream country's wage, cutoff stage prices, and the efficiency gap between the two countries. , If a country close to the bottom is only slightly more efficient than the newly joined South, the second term of equation (9) will be close to zero and thus the overall effect will be dominated by the decreased trade frictions. In this case, countries close to the bottom of the value chain are likely to experience wage losses.

The specialization pattern and changes in trade flows are illustrated in the left panel of Figure 3. As trade costs fall, first-South joins the supply chain and expands its production range. After its wage increases to a certain point, the second-South joins and repeats the pattern. During the process, output and trade flows rise steadily. The wage response can be better understood by comparing the right panels of Figure 3 and Figure 4: when technology gaps are low between South nations, i.e. efficiency gains from learning by doing are insignificant, insider-South is likely to lose when a new South joins. When learning by doing cause significant efficiency gains, the story is the opposite.
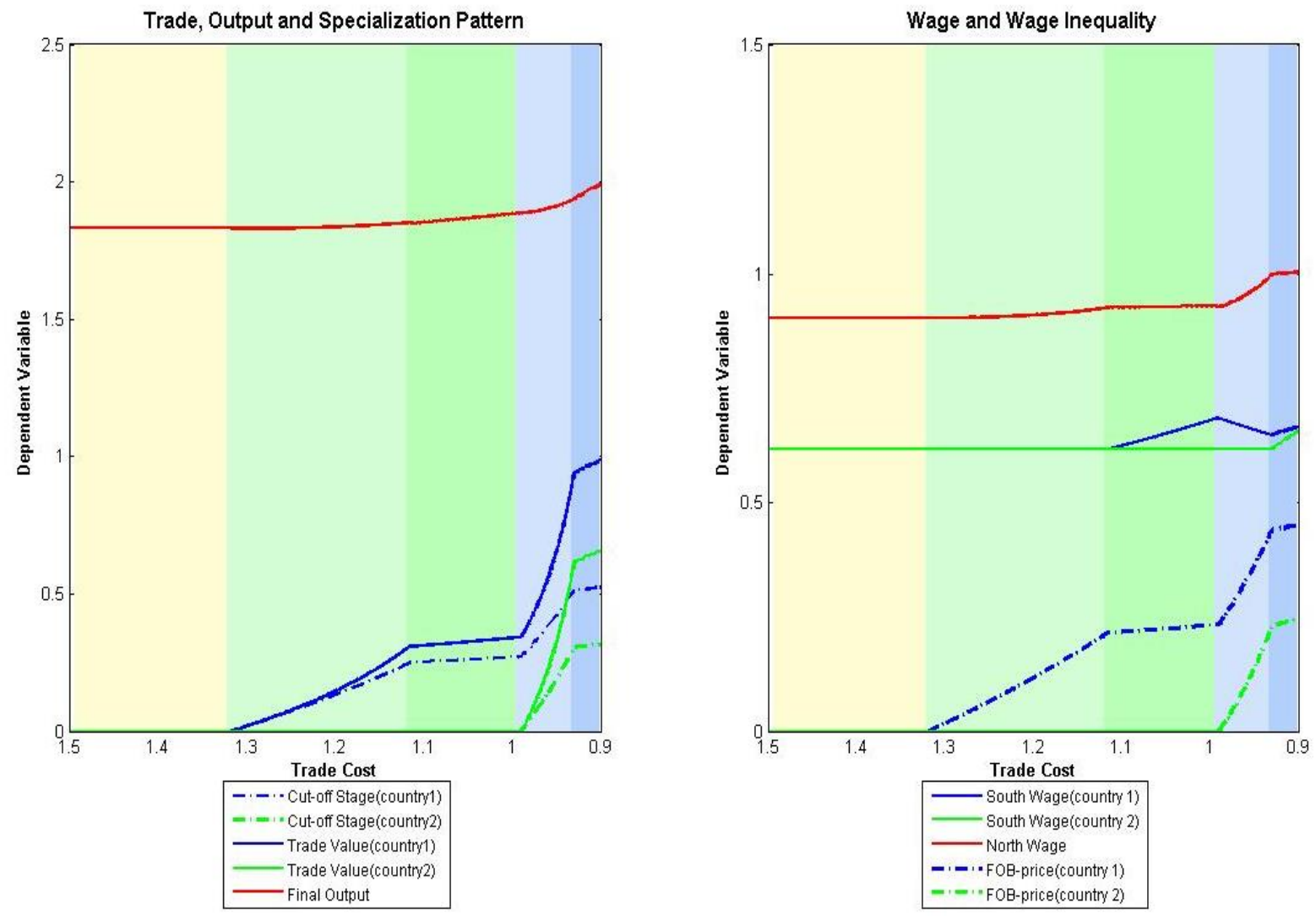

Figure 4. Consequences of decreases in trade costs (flying geese, low tech gap)

\subsection{Discussions}

The regional nature of supply-chain trade 
An important well-known feature of supply-chain trade is that it is regional rather than global (Baldwin and Lopez-Gonzalez (2013), Johnson and Noguera (2012b)). For instance, the North American auto industry is much more geographically spread than it was in the 1950s, but many auto-parts plants are still clustered within a 1,000 kilometers radius from Michigan, with major outsourcing firms located in Mexico (Klier and Rubenstein, 2008); Japan and South Korea have most of their production sharing with East Asian countries like China, Vietnam, and Thailand (Baldwin, 2008). The extension presented above captures this feature. It is somehow surprising that the successful participation in supply-chain trade for an underdeveloped South depends not only on its proximity with the hub economies, but also on other factory economies. Especially in the "flying geese" example, the success of South's entry depends solely on its proximity with the factory economy at the bottom of the chain. This is because for vertically linked industries, what matters most is the location of the direct supplier and consumer. This result is important as it provides new insights for countries that aim to develop by joining GVCs: reducing trade frictions with the developed North might not be enough; rethinking where and how to fit in GVCs needs an integrated analysis of the network and the country's proximity and technology difference with inside countries.

It is worth mentioning that, while the regionally clustered supply chain trade seems reminiscent of the spatial economy literature ${ }^{\mathrm{s}}$, the underlying mechanism here is very different. In the spatial economy literature, clustering is caused by forward and backward linkages, which crucially relies on the increasing return to scale assumption. While in my model, the production function exhibits constant returns to scale, and clustering is purely due to the interdependence of vertically linked industries. Instead of the agglomeration and dispersion effects, the only driving force here is the falling trade frictions, which alter wage gaps to attract developing countries to join.

\section{New norm of the 'flying geese pattern of development'}

As discussed briefly in subsection 3.3, introducing a simple learning-by-doing mechanism into the model creates a new "flying geese pattern". However, this is quite different from what Akamatsu originally had in mind. Written in the 1960s, Akamatsu's initial idea is rather classic: import-substitution, followed by domestic production, and finally export. My model, in contrast, sheds light on how the second unbundling transformed the industrialization pattern of an economy. Akamatsu's three-episodes of development is now the following: in the first episode, the developing South industrializes by joining GVCs, and performs a narrow set of stages - during this period, labor moves from the traditional to the modern sector, but wages remain low; in the second episode the production-range expands

\footnotetext{
${ }^{\mathrm{s}}$ See Krugman and Venables (1990), Krugman and Venables (1995a), and Krugman and Venables (1995b) among others.
} 
and South wages increase rapidly; in the last episode, the increased wage in the South attracts other developing countries to join the value chain, and the insider-South re-specializes at higher stages of the value chain and produces a narrower but more complex range. To sum up, the development of a South nation will exhibit a specialization-diversification-respecialization pattern. Throughout the process, the country is always a part of the international value chain and depends on international suppliers and consumers.

\section{Policy Implications}

The rise of North-South production-sharing leads to new policy challenges. My analyses indicate that the policy implications of supply chain participation depend on a country's development level, the existing supply-chain structure and the potential scope of technology spillovers. In this section, I briefly discuss some concerns regarding bilateral trade frictions and the importance of multilateral GVC governance. A formal analysis, however, is beyond the scope of this paper.

There are at least three types of countries facing very different challenges. The first type is developing nations that aim to join supply-chain networks. My model indicates that for those nations, what matters is not only proximity with the advanced North, but also proximity with other nations at the bottom of the value chain. In terms of policy implications, South nations can indeed reduce trade frictions with several nations to join a particular value chain, but given the complex and intertwined nature of international supply-chain networks in reality, unilaterally reducing trade frictions to all nations seems the best way to facilitate joining.

The second set of countries is developing nations that are already participants of global production networks, but want to move up the value chain. My model indicates that facilitating trade with either relatively less efficient or more efficient countries is helpful. However, reducing trade costs with outsider-countries who have similar technologies may decrease a country's welfare. This can be clearly seen from both the hub-and-spoke economy and the flying-geese case. Under this circumstance, insider-South has an incentive to against other South nations to join the supply-chain network. These results imply that the self-optimal policy for a South that is already inside the network is asymmetric: it involves facilitating trade with some countries but not with others, depending on their relative productivities and positions inside the global supply-chain networks.

The last set of issues is faced by technologically advanced nations like Japan, South Korea, and the United States, who were already industrialized before the second unbundling and now face a "hollowing out" of their industry base. My analyses indicate that this "hollowing out" may not be a concern. It might simply reflect that developed nations are specializing in more valuable stages, which is welfare-improving. For those economies, the key is to stay as a technology leader rather than prohibit offshoring. 
As depicted by the above thought experiments, when there is no learning by doing, or the technology spillover is not strong enough, insider South countries will have incentives to block other South countries from joining supply chain networks. From the North's perspective, this raises interesting questions related to free trade negotiations: with which South should the North forge a supply chain first, and should the North facilitate supply-chain trade with South nations sequentially or simultaneously? When production sharing exhibits a hub-and-spoke shape, it is clearly optimal for the North to reduce trade costs towards all South nations simultaneously; when learning-by-doing exists, the choice between sequential and simultaneous trade facilitation will probably depend on the specific learning mechanisms.

The conflicted interest among countries inside and outside supply-chain networks naturally leads to concerns on GVC governance. Bilateral trade agreements between North and South are of mutual interest and hence will be signed without problem. Regional agreements signed simultaneously by developed North and multiple underdeveloped South are also without problems. Challenges appear when we move to governance involving "inside" and "outside" countries with similar development levels - it is optimal to facilitate supplychain trade multilaterally given the aggregated welfare improvement, but this is unlikely to happen without some welfare transfers. In this case, preferential value chain participation may become a "stumbling block" for the formation of global or regional value chain networks.

\section{Conclusion}

In this paper, I developed a model with sequential production stages and international trade frictions that permits an analysis of how a decrease in trade costs shapes the interdependence between countries. I showed that as trade costs fall, the underdeveloped South joins and moves up along the value chain. Both North and South gain from decreased trade costs, though the process is non-linear. In the multi-country extensions, I showed that countries are strictly ordered along stages by their productivity within each value chain, though the specialization pattern of countries inside a supply-chain network can be complex. Successful joining of new countries depends on their proximity with insiders, as well as their existing initial industry base. In particular, in a one-North-multi-South setting, when global trade costs go down, South countries form supply chains with an advanced North sequentially. If they are of the same productivity, the production structure exhibits a hub-and-spoke shape, and joining of the new South dampens the welfare of other insider South countries. If they are of different productivity levels because of, say, learning-by-doing, the joining and development of South countries will exhibit a flying geese pattern. If the learning by doing effect is strong enough, the newly joined South will benefit everyone inside the value chain. Factory economies are 
likely to be regionally clustered in both cases. This framework can be used to analyze policy questions raised by supply-chain trade.

Even though the model presented in this paper is stylized, it matches empirical regularities on supply-chain trade and provides new insights on old development puzzles and recent GVC debates. Moreover, the model can be extended to answer other interesting questions without much complication. For instance, it provides a good framework to discuss GVC-governance related questions, such as the "building" and "stumbling" nature of deep RTAs, the optimal scope for GVC governance etc. It will be interesting to extend the model to multi-good and multi-factor settings to tackle questions related to GVC trade and factor-price adjustment. Last but not least, introducing endogenous innovation and strategic policy reforms to see how developing economies could achieve long run growth via joining GVCs is an interesting and important area for further research.

\section{Appendix}

Proof of Lemma 2-1. First consider the case in which a country has a traditional sector only. Since final good price is normalized to one and technology is of Leontief, the equilibrium wage is $w_{c}=1 / a$ for both countries.

Then consider the case in which a country has a modern sector only. Equation (5) implies:

$$
\frac{d p(s)}{d s}=\lambda_{c} p(s)+w_{c}, \text { for all } s \in(0,1]
$$

Solution of this differential equation must satisfy the boundary condition that $\mathrm{p}_{0} \equiv \mathrm{p}(\mathrm{s}=0)=$ 0 and $\mathrm{P} \equiv \mathrm{p}(\mathrm{s}=1)=1$. From which I derive the wage condition (equation (6)) and the price equation of each stage (equation (8)).

Since $\frac{\lambda_{S}}{e^{\lambda} S-1}>a>\frac{\lambda_{N}}{e^{\lambda_{N-1}}}$, the modern and traditional productions cannot co-exist. Moreover, if South has the modern production, firms will have an incentive to deviate and produce using the traditional technology, as it generates positive profits given market wages. Hence when South and North organize production separately, the South would only have the traditional sector while the North could have either of the sectors. It is easy to verify that given the industry structure, wages and prices, not a single firm will find it optimal to enter the alternative sector. So those Equilibria are stable. Hence Lemma 2-1 is proved.

Next I provide the proof for the quantity firms produce using the modern technology. As there is no international production sharing, equation (1) implies the following differential equation:

$$
\frac{d Q(s)}{d s}=-\lambda_{c} Q(s) \text {, for all } s \in(0,1]
$$

in addition, the labor market clearing condition implies

$$
\int_{0}^{1} Q(s) d s=L_{c}
$$

Solving equation (29) together with the boundary condition provided by equation (23), I obtain the 


\section{Yuan Zi}

quantity equation (7).

Proof of Lemma 2-2. I prove Lemma 2-2 in three steps: I first find a local feasible production sharing structure that can be supported by wages, and then I check for global stability; finally, I check whether this stability is robust to alternative traditional technology.

Step1. If there is any production sharing it must be that South upstream suppliers serve North downstream firms. I decompose the proof to three sub-steps.

Firstly, notice that perfect competition requires:

$$
\begin{array}{cc}
p_{i}(s)=p_{i}(s-d s)\left(1+\lambda_{i} d s\right)+w_{i} d s & \text { for } i=j, \text { at any } s \\
p_{i}(s)=\tau p_{j}(s-d s)\left(1+\lambda_{i} d s\right)+w_{i} d s & \text { for } i \neq j, \text { at any } s
\end{array}
$$

Thus, it is easy to show that price is strictly increasing along stages.

Secondly, it would not be feasible for a firm to have both a consumer and supplier from abroad. Suppose that a firm in country $i$ occupies stage $s$, and demands intermediates from country $j$ and serves clients also from country $j$. For this firm to find it optimal to operate, it must be that downstream firms in country $j$ find it cheaper to buy intermediates from it than from its potential competitors in country $j$. Formally, this means:

$$
\tau\left(\tau p_{j}(s-d s)\left(1+\lambda_{i} d s\right)+w_{i} d s\right) \leq p_{j}(s-d s)\left(1+\lambda_{j} d s\right)+w_{j} d s
$$

rearranging terms I get:

$$
p_{j}(s-d s)\left(\tau^{2}-1\right) \leq\left[p_{j}(s-d s)\left(\lambda_{j}-\lambda_{i} \tau^{2}\right)+\left(w_{j}-\tau w_{i}\right)\right] d s
$$

However, this cannot hold when $d s$ is infinitely small. Therefore I prove by contradiction. This result shares the same intuition with (Baldwin and Venables, 2013), who argue that fragments below a minimum size will not be offshored.

Finally, if North firms in stage $s$ serve South firms in stage $s+d s$, North firms also operate at stage $s-d s$, while South firms operate at stage $s+d s$. Then the necessary ${ }^{t}$ condition for this production sharing structure to hold is:

$$
\begin{gathered}
\tau p_{\mathrm{N}}(s-d s)\left(1+\lambda_{S} d s\right)+w_{S} d s \geq \tau p_{N}(s-d s)\left(1+\lambda_{N} d s\right)+\tau w_{N} d s \\
\tau p_{N}(s)\left(1+\lambda_{N} d s\right)+\tau w_{N} d s \geq \tau p_{\mathrm{N}}(s)\left(1+\lambda_{S} d s\right)+w_{S} d s
\end{gathered}
$$

That is, potential South competitors will not find it profitable to enter at stage $s$, attain input from North and serve domestically. Similarly, potential North competitors will not find it profitable to enter at stage $s+d s$ and serve South firms at stage $s+2 d s$. The above equations imply:

$$
p_{N}(s-d s) \geq\left(\tau w_{N}-w_{S}\right) / \tau\left(\lambda_{S}-\lambda_{N}\right) \geq p_{N}(s)
$$

which contradicts the strictly increasing prices.

Analogously, if there is any production sharing where the South serves the downstream North at stage $s$, wages in the two countries must satisfy:

$$
\begin{gathered}
\tau p_{S}(s-d s)\left(1+\lambda_{N} d s\right)+w_{N} d s \geq \tau p_{S}(s-d s)\left(1+\lambda_{S} d s\right)+\tau w_{S} d s \\
\tau p_{S}(s)\left(1+\lambda_{S} d s\right)+\tau w_{S} d s \geq \tau p_{S}(s)\left(1+\lambda_{N} d s\right)+w_{N} d s
\end{gathered}
$$

Equations (24) and (25) are compatible with each other.

\footnotetext{
${ }^{\mathrm{t}}$ For sufficiency, it is easy to verify the feasible equilibriums are stable.
} 
Step2. Without considering the traditional sector, there are two production sharing equilibria: in one, there exists a stage $\tilde{s} \in(0,1)$ such that $Q_{S}(s)>0$ if and only if $s \in(0, \tilde{s}]$, and $Q_{N}(s)>0$ if and only if $s \in(\widetilde{s}, 1]$; in the other, there exists a stage $\tilde{s} \in(0,1)$ such that $Q_{S}(s)>0$ for all $s \in(0,1]$, and $\mathrm{Q}_{\mathrm{N}}(\mathrm{s})>0$ if and only if $\mathrm{s} \in(\widetilde{\mathrm{s}}, 1]$.

Let $d s$ goes to infinitesimal, equations (24) and (25) imply that if there is any production sharing where the South serves the downstream North at stage $s$, wages in the two countries must satisfy:

$$
w_{N}=\tau w_{S}+\tau p(s)\left(\lambda_{S}-\lambda_{N}\right)
$$

As price increases strictly along stages and perfectly competitive labor markets equalize national wages, intermediates can move across countries at most once. Moreover, as proved before, the direction can only be from South to North. This leaves us four possible global-supply-chain structures that satisfy the above local properties.

Type 1. There exists a stage $\tilde{s} \in(0,1)$ such that $Q_{S}(s)>0$ if and only if $s \in(0, \tilde{s}]$, and $Q_{N}(s)>0$ if and only if $s \in(\tilde{s}, 1]$.

That is, South specializes in upstream stages and North specializes in downstream stages. In this case equilibrium is characterized as:

$$
\begin{gathered}
w_{N}=\tau w_{S}+\tau p(\tilde{s})\left(\lambda_{S}-\lambda_{N}\right) \\
P(s ; s \leq \tilde{s})=\left(e^{\lambda_{S} s}-1\right)\left(\frac{W_{S}}{\lambda_{S}}\right) \\
P(s ; s \geq \tilde{s})=e^{\lambda_{N}(s-\tilde{s})} \tau P(\tilde{s})+\left(e^{\lambda_{N}(s-\tilde{s})}-1\right)\left(\frac{W_{N}}{\lambda_{N}}\right)
\end{gathered}
$$

From the first sub-result in step 1, Lemma 2-1, I know that no firm will find it optimal to enter a stage at which it has no domestic supply or demand linkages. Therefore, no firm in another country will find it optimal to enter a stage away from stage $\tilde{s}$. Around stage $\tilde{s}$ I also know that no firm would want to deviate from current production structure as shown in the first part of stage 2, Lemma 2-2.

Type 2. North Specializes in downstream stages and South produce in all stages.

In this case, South serves both countries at upstream stages, while the downstream firms are served by domestic suppliers. Equilibrium satisfies:

$$
\begin{gathered}
w_{S}=\frac{\lambda_{S}}{e^{\lambda_{S}}-1} \\
w_{N}=\tau w_{S}+\tau p(\tilde{s})\left(\lambda_{S}-\lambda_{N}\right) \\
p_{S}(s)=\left(e^{\lambda_{S} s}-1\right)\left(\frac{w_{S}}{\lambda_{S}}\right) \\
p_{N}(s ; s \geq \tilde{s})=e^{\lambda_{N}(s-\tilde{s})} \tau p(\tilde{s})+\left(e^{\lambda_{N}(s-\tilde{s})}-1\right)\left(\frac{w_{N}}{\lambda_{N}}\right)
\end{gathered}
$$

Similar to the proof for type 1, one can show that no firm will find it optimal to deviate below and around stage $\tilde{s}$. Above the stage $\tilde{s}$, stability requires $1 / \tau \leq p_{S}(s) / p_{N}(s) \leq \tau$ for all $s \geq \tilde{s}$. To see this clearer, assume $p_{S}(s) / p_{N}(s)>\tau$ at a stage $s>\tilde{s}$, then South firms in stage $s+d s$ will only demand 


\section{Yuan Zi}

inputs from North firms due to cost minimization, which will cause type 2 equilibrium to break down. It is easy to check that $1 / \tau \leq p_{S}(s) / p_{N}(s) \leq \tau$ holds for the type 2 case.

Type 3. South Specializes in upstream stages and North produce in all stages.

In this case, equilibrium is characterized as :

$$
\begin{gathered}
w_{N}=\frac{\lambda_{N}}{e^{\lambda_{N}}-1} \\
w_{N}=\tau w_{S}+\tau p(\tilde{s})\left(\lambda_{S}-\lambda_{N}\right) \\
p_{N}(s)=\left(e^{\lambda_{N} s}-1\right)\left(\frac{w_{N}}{\lambda_{N}}\right) \\
p_{S}(s ; s \leq \tilde{s})=\left(e^{\lambda_{S} s}-1\right)\left(\frac{w_{S}}{\lambda_{S}}\right)
\end{gathered}
$$

Similar to the proofs above, no firm will find it optimal to deviate above and around stage $\tilde{s}$. Below the stage $\tilde{s}$, stability requires $1 / \tau \leq p_{S}(s) / p_{N}(s) \leq \tau$. Notice that at stage $\tilde{s}$, for both North and South firms to serve downstream North firms we must have $1 / \tau=p_{S}(\tilde{s}) / p_{N}(\tilde{s})$. However, given wage, equations (36) and (37) imply that $p_{S}(s) / p_{N}(s)$ is an increasing function of $s$. Therefore $p_{S}(s) /$ $p_{N}(s)<1 / \tau$ for $s \leq \tilde{s}$, which contradicts $1 / \tau \leq p_{S}(s) / p_{N}(s)$.

Type 4. Both countries produce in all stages, and at stage $\tilde{S} \in(0,1)$, North firms request some inputs from South.

Using the same proof for type 3 one can easily show the infeasibility of type 4 .

Step3. Type 2 equilibrium in step 2 is not feasible with the presence of a traditional technology. This statement is obviously true, as in step1 of Lemma 2-1, I prove that South cannot have the modern sector given that it is less efficient than the alternative traditional technologies.

Hence we finished the proof for Lemma 2-2.

Proof of Proposition 1-1. I decompose the proof of Proposition 1-1 into two parts; I first show that a decrease in $\tau$ leads to an increase of wages in the North, and then I show that a decrease in $\tau$ increases the cutoff stage $\tilde{s}$ and the total amount of labor employed by the modern sector in the South.

Step1. A decrease in $\tau$ leads to an increase of $w_{N}$.

Equation (26) explains that:

$$
p(\tilde{s})=\left(w_{N}-\tau w_{S}\right) / \tau\left(\lambda_{S}-\lambda_{N}\right)
$$

Plugging equation (38) into equation (16) to substitute $p(\tilde{s})$, and writing $\tilde{s}$ as a function of $w_{N}$, and $\tau$, I get:

$$
\tilde{s}=\ln \left(\frac{\lambda_{S}\left(w_{N}-\tau w_{S}\right)}{\tau\left(\lambda_{S}-\lambda_{N}\right) w_{S}}+1\right) / \lambda_{S}
$$

Using equations (38) and (39) to substitute $p(\tilde{s})$ and $\tilde{s}$ in equation (17), I obtain: 


$$
e^{\lambda_{N}\left[1-\frac{\ln \left(\frac{\lambda_{S}\left(w_{N}-\tau w_{S}\right)}{\tau\left(\lambda_{S}-\lambda_{N}\right) w_{S}}+1\right)}{\lambda_{S}}\right]} \frac{w_{N}-\tau w_{S}}{\lambda_{S}-\lambda_{N}}+\left(e^{\lambda_{N}\left[1-\frac{\ln \left(\frac{\lambda_{S}\left(w_{N}-\tau w_{S}\right)}{\tau\left(\lambda_{S}-\lambda_{N}\right) w_{S}}+1\right)}{\lambda_{S}}\right]}-1\right)\left(\frac{W_{N}}{\lambda_{N}}\right)=1
$$

Total differentiating equation (40), provides:

$$
\begin{gathered}
\frac{e^{\lambda_{N}(1-\tilde{s})}}{\lambda_{S}-\lambda_{N}} d w_{N}-e^{\lambda_{N}(1-\tilde{s})} \frac{w_{N}-\tau w_{S}}{\lambda_{S}-\lambda_{N}} \frac{\partial \tilde{s}}{\partial w_{N}} d w_{N}+\frac{e^{\lambda_{N}(1-\tilde{s})}-1}{\lambda_{N}} d w_{N}-e^{\lambda_{N}(1-\tilde{s})} \frac{w_{N}}{\lambda_{N}} \frac{\partial \tilde{s}}{\partial w_{N}} d w_{N} \\
-e^{\lambda_{N}(1-\tilde{s})} \frac{w_{S}}{\lambda_{S}-\lambda_{N}} d \tau-e^{\lambda_{N}(1-\tilde{s})} \frac{w_{N}-\tau w_{S}}{\lambda_{S}-\lambda_{N}} \frac{\partial \tilde{s}}{\partial \tau} d \tau-e^{\lambda_{N}(1-\tilde{s})} \frac{w_{N}}{\lambda_{N}} \frac{\partial \tilde{s}}{\partial \tau} d \tau=0
\end{gathered}
$$

Differentiating equation (39) with respect to $\tau$, I obtain:

$$
\frac{\partial \tilde{s}}{\partial \tau}=-\frac{w_{N}}{\tau\left(\lambda_{S} w_{N}-\tau \lambda_{N} w_{S}\right)}<0
$$

Similarly, differentiate equation (39) with respect to $w_{N}$, results in;

$$
\frac{\partial \tilde{s}}{\partial w_{N}}=\frac{1}{\lambda_{S} w_{N}-\tau \lambda_{N} w_{S}}>0
$$

Finally, plugging equations (42) and (43) into equation (41) and collecting terms, I get:

$$
\frac{e^{\lambda_{N}(1-\tilde{s})}}{\lambda_{S}-\lambda_{N}} d w_{N}-e^{\lambda_{N}(1-\tilde{s})} \frac{1}{\left(\lambda_{S}-\lambda_{N}\right) \lambda_{N}} d w_{N}+\frac{e^{\lambda_{N}(1-\tilde{s})}-1}{\lambda_{N}} d w_{N}=M d \tau
$$

where $M=\frac{e^{\lambda_{N}(1-\tilde{s})}}{\lambda_{S}-\lambda_{N}} w_{S}+e^{\lambda_{N}(1-\tilde{s})} \frac{w_{N}-\tau w_{S}}{\lambda_{S}-\lambda_{N}} \frac{\partial \tilde{s}}{\partial \tau}+e^{\lambda_{N}(1-\tilde{s})} \frac{w_{N}}{\lambda_{N}} \frac{\partial \tilde{s}}{\partial \tau}$. Since $w_{N}-\tau w_{S}>0$ and $\lambda_{N} \in(0,1)$, then $M=\frac{e^{\lambda_{N}(1-\tilde{s})}}{\lambda_{S}-\lambda_{N}}\left(w_{S}-\frac{w_{N} \lambda_{S}-\tau w_{S} \lambda_{N}}{\lambda_{N}} \frac{w_{N}}{\tau\left(\lambda_{S} w_{N}-\tau \lambda_{N} w_{S}\right)}\right)=\frac{e^{\lambda_{N}(1-\tilde{s})}}{\lambda_{S}-\lambda_{N}}\left(w_{S}-\frac{w_{N}}{\tau \lambda_{N}}\right)<0$.

Note also that since $\frac{e^{\lambda_{N}(1-\tilde{s})}}{\lambda_{S}-\lambda_{N}} d w_{N}-e^{\lambda_{N}(1-\tilde{s})} \frac{1}{\left(\lambda_{S}-\lambda_{N}\right) \lambda_{N}}+\frac{e^{\lambda_{N}(1-\tilde{s})}-1}{\lambda_{N}}>0$, then $\frac{\partial w_{N}}{\partial \tau}<0$, which means that a decrease in $\tau$ leads to an increase of real wages in the North.

Step2. A decrease in $\tau$ leads to an increase of $\tilde{s}$ and $L_{S}^{M}$.

I proceed to step 2 with proof by contradiction. Suppose for $\tau^{\prime}<\tau$ I have $\tilde{s}^{\prime}<\tilde{s}$, since there is no wage change in the South because of the traditional sector, equation (16) implies $p(\tilde{s})^{\prime}<p(\tilde{s})$. However, if that is the case, equation (9) implies $w_{N}{ }^{\prime}<w_{N}$, which contradicts the proof in step 1. Therefore I must have $\tilde{s}^{\prime}>\tilde{s}$.

Equation (14), (15) and (18) implies:

$$
L_{S}^{M}=\frac{\tau \lambda_{N} L_{N}}{1-e^{-\lambda_{N}(1-\tilde{s})}} \frac{e^{\lambda_{S} \tilde{s}}-1}{\lambda_{S}}
$$

Differentiating equation (39) with respect to $\tau$, I obtain:

$$
\begin{aligned}
\frac{\partial L_{S}^{M}}{\partial \tau} & =\frac{\lambda_{N} L_{N}\left(e^{\lambda_{S} \tilde{s}}-1\right)}{\left(1-e^{-\lambda_{N}(1-\tilde{s})}\right) \lambda_{S}}+\left(\lambda_{S}+e^{-\lambda_{N}(1-\tilde{s})}\left(\lambda_{N}-\lambda_{S}\right)\right) \frac{\tau \lambda_{N} L_{N}\left(e^{\lambda_{S} \tilde{s}}-1\right)}{\left(1-e^{-\lambda_{N}(1-\tilde{s})}\right)^{2} \lambda_{S}} \frac{\partial \tilde{s}}{\partial \tau} \\
& =\frac{\lambda_{N} L_{N}\left(e^{\lambda_{S} \tilde{s}}-1\right)}{\left(1-e^{-\lambda_{N}(1-\tilde{s})}\right) \lambda_{S}}\left[1-\frac{w_{N}}{\lambda_{S} w_{N}-\tau \lambda_{N} w_{S}}\left(\lambda_{S}+\frac{e^{-\lambda_{N}(1-\tilde{s})} \lambda_{N}}{1-e^{-\lambda_{N}(1-\tilde{s})}}\right)\right]
\end{aligned}
$$

As $w_{N} /\left(\lambda_{S} w_{N}-\tau \lambda_{N} w_{S}\right)>1 / \lambda_{S}$ and $\lambda_{S}+\frac{e^{-\lambda_{N}(1-\tilde{s})} \lambda_{N}}{1-e^{-\lambda_{N}(1-\tilde{s})}}>\lambda_{S}$, then $\frac{\partial L_{S}^{M}}{\partial \tau}<0$. Thus, for $\tau^{\prime}<\tau, L_{S}^{M^{\prime}}>L_{S}^{M}$. 


\section{Yuan Zi}

Proof of Proposition 1-2. I decompose the proof of Proposition 1-2 into three steps; I first show that a decrease in $\tau$ leads to an increase in final output and the South moving up the value chain, then I show that this leads to an increase of wages in both the South and the North. In the last step, I show that wage inequality between the two decreases.

Step1. A decrease in $\tau$ leads to an increase of $\tilde{s}$ and $Q(1)$.

From equation (19) I know that $\partial Q_{0} / \partial \tilde{s}<0$. Using equations (19) and (15) to eliminate $\tilde{s}$, I obtain:

$$
Q_{1}=Q_{0}-\lambda_{S} L_{S}
$$

Equations (19), (14), and (48) therefore implies:

$$
1=-\frac{1}{\lambda_{C}} I_{n}\left(1-\frac{\lambda_{N} L_{N}}{Q_{0}-\lambda_{S} L_{S}}\right)-\frac{1}{\lambda_{S}} \ln \left(1-\frac{\lambda_{S} L_{S}}{Q_{0}}\right)
$$

From equation (48), it is easy to verify that $\partial Q_{0} / \partial \tau>0$. Therefore a decrease in $\tau$ will cause a decrease in $Q_{0}$, and therefore an increase in $\tilde{s}$.

Final good production can be written as :

$$
Q(1)=\frac{1}{\tau} Q_{0} e^{-\left(\lambda_{S} \tilde{s}+\lambda_{N}(1-\tilde{s})\right)}
$$

Combining with equation (19), I obtain:

$$
Q(1)=\frac{\lambda_{S} L_{S}}{\tau} \cdot \frac{e^{-\lambda_{N}(1-\tilde{s})}}{e^{\lambda_{S} \tilde{s}}-1}
$$

Next, I use equation (19) to eliminate $Q_{0}$ in equation (48) and get:

$$
-\frac{1}{\lambda_{N}} \ln \left(1-\frac{\lambda_{N} L_{N}\left(1-e^{-\lambda_{S} \tilde{s}}\right) \tau}{\lambda_{S} L_{S} e^{-\lambda_{S} \tilde{s}}}\right)+\tilde{s}=1
$$

which provides a direct relationship between $\tilde{s}$ and $\tau$ :

$$
\tau=\frac{\left(1-e^{-\lambda_{N}(1-\tilde{s})}\right) e^{-\lambda_{S} \tilde{s}}}{1-e^{-\lambda_{S} \tilde{s}}} \cdot \frac{\lambda_{S} L_{S}}{\lambda_{N} L_{N}}
$$

Totally differentiating equation (52), I obtain:

$$
d \tau=\frac{\lambda_{S} L_{S}}{\lambda_{N} L_{N}} \frac{-\lambda_{N} e^{-\lambda_{N}(1-\tilde{s})} e^{-\lambda_{S} \tilde{s}}\left(1-e^{-\lambda_{S} \tilde{s}}\right)-\lambda_{S}\left(1-e^{-\lambda_{N}(1-\tilde{s})}\right) e^{-\lambda_{S} \tilde{s}}}{\left(1-e^{-\lambda_{S} \tilde{s}}\right)^{2}} d \tilde{s} \equiv \alpha d \tilde{s}
$$

where $\frac{\lambda_{S} L_{S}}{\lambda_{N} L_{N}} \frac{-\lambda_{N} e^{-\lambda_{N}(1-\tilde{s})} e^{-\lambda_{S} \tilde{s}}\left(1-e^{-\lambda_{S} \tilde{s}}\right)-\lambda_{S}\left(1-e^{-\lambda_{N}(1-\tilde{s})}\right) e^{-\lambda_{S} \tilde{s}}}{\left(1-e^{-\lambda_{S} \tilde{s}}\right)^{2}} \equiv \alpha<0$.

Equations (52) and (53) are important as they will be used for proofs repeatedly.

Totally differentiating equation (50), I obtain:

$$
d Q(1)=-\frac{d \tau}{\tau} Q(1)+Q(1)\left(\left(\lambda_{N}-\lambda_{S}\right)-\frac{\lambda_{S}}{e^{\lambda_{S} \tilde{s}}-1}\right) d \tilde{s}
$$

Using equation (53) to substitute $d \tilde{s}$ in equation (54), and doing some algebra, one can show that $d Q(1) / d \tau<0$.

Therefore as trade $\operatorname{cost} \tau$ goes down, the South moves up along the supply chain and total output of final goods increases.

Step2. A decrease in $\tau$ leads to an increase of $w_{S}$ and $w_{N}$.

Writing $w_{N}$ as a function of $P(\tilde{S})$ and $w_{S}$ using equation (9) and substituting into the price equation 
(17), and then resubstitute $P(\tilde{s})$ as a function of $w_{S}$ using equation (16), and collecting terms, I get:

$$
\frac{\tau W_{S}}{\lambda_{S} \lambda_{N}}\left\{\left(e^{\lambda_{S} \tilde{s}}-1\right)\left[\lambda_{S}\left(e^{\lambda_{N}(1-\tilde{s})}-1\right)+\lambda_{N}\right]+\lambda_{S}\left(e^{\lambda_{N}(1-\tilde{s})}-1\right)\right\}=1
$$

Then, using equations (55) and (52) to substitute $\tau$, provides:

$$
\left(\frac{L_{S}}{\lambda_{N}^{2} L_{N}}\right) * w_{S} * \varphi=1
$$

where $\varphi \equiv \frac{\left(1-\mathrm{e}^{-\lambda_{\mathrm{N}}(1-\tilde{\mathrm{s}})}\right)}{\mathrm{e}^{\lambda_{S} \tilde{s}_{-1}}}\left\{\left(e^{\lambda_{S} \tilde{s}}-1\right)\left[\lambda_{S}\left(e^{\lambda_{N}(1-\tilde{s})}-1\right)+\lambda_{N}\right]+\lambda_{S}\left(e^{\lambda_{N}(1-\tilde{s})}-1\right)\right\}$

With some simple algebra one can show that $\frac{\partial \varphi}{\partial \tilde{s}}<0$, and thus $\frac{\partial w_{S}}{\partial \tilde{s}}>0$. Furthermore, Step1 of Proposition 1-2 shows that a decrease in $\tau$ leads to an increase in the cutoff stage $\tilde{s}$, and hence results in an increase of South wages $w_{S}$.

Similarly, one can write the final good price equation as a function of $w_{N}$ and $\tilde{s}$ as follows:

$$
\frac{w_{N}}{\lambda_{S} \lambda_{N}}\left[1+\frac{\left(\lambda_{S}-\lambda_{N}\right)}{\lambda_{S}}\left(e^{\lambda_{S} \tilde{s}}-1\right)\right]^{-1}\left[\lambda_{S} e^{\lambda_{N}(1-\tilde{s})+\lambda_{S} \tilde{s}}-\left(\lambda_{S}-\lambda_{N}\right) e^{\lambda_{S} \tilde{s}}-\lambda_{N}\right]=1
$$

Denote $\vartheta \equiv\left[1+\frac{\left(\lambda_{S}-\lambda_{N}\right)}{\lambda_{S}}\left(e^{\lambda_{S} \tilde{s}}-1\right)\right]^{-1}\left[\lambda_{S} e^{\lambda_{N}(1-\tilde{s})+\lambda_{S} \tilde{s}}-\left(\lambda_{S}-\lambda_{N}\right) e^{\lambda_{S} \tilde{s}}-\lambda_{N}\right]$, then one can show that $\frac{\partial \vartheta}{\partial \tilde{s}}<0$. Thus, $\frac{\partial w_{N}}{\partial \tilde{s}}>0$, which implies that a decrease in $\tau$ leads to an increase in the cutoff stage $\tilde{S}$, and hence results in an increase of Nouth wages $w_{N}$.

Step3. A decrease in $\tau$ leads to a decrease in wage inequality $w_{N} / w_{S}$.

We use equations (9) and (16) to substitute $P(\tilde{S})$, and write the wage ratio as follows:

Total differentiating both sides I get:

$$
\frac{w_{N}}{w_{S}}=\tau+\tau \frac{e^{\lambda_{S} \tilde{s}}-1}{\lambda_{S}}\left(\lambda_{S}-\lambda_{N}\right)
$$

$$
d \frac{w_{N}}{w_{S}}=\left(1+\frac{e^{\lambda_{S} \tilde{s}}-1}{\lambda_{S}}\left(\lambda_{S}-\lambda_{N}\right)\right) d \tau+\tau e^{\lambda_{S} \tilde{s}}\left(\lambda_{S}-\lambda_{N}\right) \frac{\partial \tilde{s}}{\partial \tau} d \tau
$$

Substituting equation (53) into equation (59) for $\frac{\partial \tilde{s}}{\partial \tau}$, and collecting terms, I obtain:

$$
d \frac{w_{N}}{w_{S}}=\left[\frac{e^{\lambda_{S} \tilde{s}}-1}{\lambda_{S}}\left(\lambda_{S}-\lambda_{N}\right) \Omega+1\right] d \tau
$$

where $\Omega \equiv \frac{\lambda_{S}\left(e^{\lambda} S^{\tilde{s}}-1\right)}{\lambda_{N}\left(e^{\lambda_{S}}-1\right)+\lambda_{S}\left(e^{\lambda_{N}(1-\tilde{s})}-1\right) e^{\lambda_{S} \tilde{s}}}>0$, and thus $\left[\frac{e^{\lambda_{S} \tilde{s}}-1}{\lambda_{S}}\left(\lambda_{S}-\lambda_{N}\right) \Omega+1\right]>0$, which also implies $\partial \frac{w_{N}}{w_{S}} / \partial \tau>0$, meaning that the wage gap decreases as trade friction decreases.

Proof of Lemma 3-1. Note that Lemma 3-1 is a straightforward extension of Lemma 2-2. First, according to the definition of value chain provided above, a stage within a value chain is occupied by a single country. Second, according to the proof of Lemma 2-2, step1, every time there is a split of tasks between countries, it must be that the more efficient country occupies the later stages. This local property holds at every stage of the value chain. Hence I prove that countries are strictly ordered according to their defect rates along the value chain. Lastly, by writing down countries' wage equations and the price-stage function, one can prove that given countries wage, there can only be one way of slicing the value chain across countries as parameters are exactly identified. Hence a set of countries 


\section{Yuan Zi}

can only organize one particular value chain.

Proof of Proposition 2-3. I decompose the proof of Proposition 2-3 into three steps. I first show that when countries are fully specialized, the problem can be re-characterized as in the two country model, with the size of the South equaling the sum of trade-friction-adjusted sizes of all joined South countries. Then I show that an increase in this size leads to a decrease of South wagse but an increase (weakly) of North wages. In the final step, I show that the newly joined South, irrespective of its proximity with the North, causes a decrease of South wages but an increase (weakly) of North wages.

Step1. Re-characterize the problem as the two-country model.

In the case with multiple South countries, equations (9) and (16) can be represented as:

$$
\begin{gathered}
w_{N}=\tau_{N S_{i}} w_{S_{i}}+\tau_{N S_{i}} P_{S_{i}}(\tilde{s})\left(\lambda_{S}-\lambda_{N}\right) \\
P_{S_{i}}(\tilde{s})=\left(e^{\lambda_{S} \tilde{s}}-1\right)\left(\frac{w_{S_{i}}}{\lambda_{S}}\right)
\end{gathered}
$$

Since there is a single North country and the cutoff stage is the same for every South country inside the supply-chain network, equations (61) and (62) imply $w_{S_{i}} \tau_{N S_{i}}=w_{S_{j}} \tau_{N S_{j}}$. That is, the wage difference between the two South is proportional to their proximity difference with the North. I use the insider South having the highest $\tau$ with the North as numeraire, and denote its wage as $w_{S}$, and its trade friction with the North as $\tau$. Then, compared to the equilibrium characterized by Lemma 2-4, I have price equations (equations (9), (16) and (17)) unchanged. Furthermore, equations (19), (15) and (14) respectively become:

$$
\begin{gathered}
\tilde{s}=-\frac{1}{\lambda_{S}} \ln \left(1-\frac{\lambda_{S} L_{S_{i}}}{Q_{0_{S_{i}}}}\right) \\
1-\tilde{s}=-\frac{1}{\lambda_{N}} \ln \left(1-\frac{\lambda_{N} L_{N}}{\sum\left(Q_{1_{S}} / \tau_{N S_{i}}\right)}\right) \\
Q_{1_{S_{i}}}=e^{-\lambda_{S} \tilde{s}} Q_{0_{S_{i}}}
\end{gathered}
$$

where $Q_{0_{S_{i}}}$ and $Q_{1_{S_{i}}}$ indicate the quantities of the initial input and the last-stage intermediates produced by the South country $i$, respectively. Notice that combining equations (63) and (65), $\sum\left(Q_{1_{S_{i}}} / \tau_{N S_{i}}\right)$ can be written as:

$$
\sum\left(Q_{1_{S_{i}}} / \tau_{N S_{i}}\right)=e^{-\lambda_{S} \tilde{s}} \sum\left(Q_{0_{S_{i}}} / \tau_{N S_{i}}\right)=\frac{1}{\tau} \frac{e^{-\lambda_{S} \tilde{s}} \lambda_{S}}{1-e^{-\lambda_{S} \tilde{s}}} \sum\left(\tau L_{S_{i}} / \tau_{N S_{i}}\right)
$$

Hence the equilibrium can exactly be characterized by equations (9)-(17), with $\tau$ and $w_{S}$ replaced by the numeraire South's trade friction and its wages, and size of the South replaced by a trade friction weighted sum of all South countries, i.e. $L_{S}=\sum\left(\frac{\tau}{\tau_{N S_{i}}} L_{S_{i}}\right)$. The wages of other insider South can be calculated directly from the equation $w_{S_{i}} \tau_{N S_{i}}=w_{S_{j}} \tau_{N S_{j}}$.

Step2. Increasing the aggregate South size decreases the numeraire South wage, increases the North wage, and increases (weakly) the cutoff stage $\tilde{s}$.

Given the results proved in step1, the problem can be preceded in the two country setting. I further decompose the proof into two cases. 
Case 1. The aggregated South is not fully specialized.

In this case, the result is trivial: increased South labor force will be absorbed by the traditional sector, while the cutoff stage, the North wage and the wage of the numeraire South do not change.

Case II. The aggregated South is fully specialized.

In this case, the increase of the cutoff stage follows directly from equation (19). Then, equation (58) implies that the wage gap between North and South widens. Using equation (40) and some algebra, one can show that $\frac{\partial w_{N}}{\partial w_{S}}<0$. Together with the results derived from equations (40) and (58), it is clear that North wage increases and South wage decreases.

Combining the two cases, one can conclude that an increase in the aggregate South size decreases the numeraire South wage, increases the North wage, and increases the cutoff stage $\tilde{s}$ weakly.

Step3. The entry of a new South increases real wages of the North but decreases real wages of other insider-South. All South countries move up the value chain.

The increase of cutoff-stages and the increase of North wages (weakly) directly follow the result of step2. Note that the newly joined South's wage always weakly increase as the new wage cannot be lower than its reservation wage $\frac{1}{a}$. I denote the insider South of the highest and lowest proximity with the North as $S_{h}$ and $S_{l}$ respectively. In addition, I denote the outside South as $S_{o}$, and the insider South with which the outside South joined as $S_{i}$. Then, the proof for the joining effect on other South wages can be decomposed into five cases.

Case I. $\tau_{N S_{O}}>\tau_{N S_{l}}$, and after joining, $S_{o}$ is incompletely specialized.

If $\mathrm{S}_{\mathrm{o}}$ is incompletely specialized and is the least proximate country with the North, then all other insider South are completely specialized. The joining condition for $S_{o}$ is $w_{S_{i}} \geq \tau_{S_{o} S_{i}} w_{S_{o}}$. I denote the postjoin wages with an asterisk. Note that the wage proportionality holds after joining, and thus the new wage condition is $\tau_{N S_{i}} w_{S_{i}}^{*}=\tau_{N S_{o}} w_{S_{o}}^{*}$. Since $S_{o}$ is incompletely specialized, $w_{S_{o}}^{*}=w_{S_{o}}=\frac{1}{a}$. Together with the triangular inequality $\tau_{N S_{i}} \tau_{S_{O} S_{i}}>\tau_{N S_{o}}$, one can show that $w_{S_{i}}^{*}<w_{S_{i}}$. Since South wages are proportional, all other inside South's wages decrease as well.

Case II. $\tau_{N S_{o}}>\tau_{N S_{l}}$, and after joining, $S_{o}$ is completely specialized.

Similarly to case I, all other South are completely specialized. Hence this case is equivalent to an enlargement of the aggregate South. Applying the result of step2, the numeraire country $S_{l}$ 's wage $w_{l}$ must weakly decrease. Hence all inside South's wages decrease proportionally.

Case III. $\tau_{N S_{o}}<\tau_{N S_{l}}$, and after joining, $S_{l}$ is incompletely specialized.

When $S_{1}$ is incompletely specialized, its wage equals the reservation wage $\frac{1}{a}$. This means that (1) its wage weakly decreases and (2) all other South are completely specialized - thus wage proportionality applies. These two together imply that all inside South's wages weakly decrease.

Case IV. $\tau_{N S_{o}}<\tau_{N S_{l}}$, and after joining, $S_{l}$ is completely specialized.

The proof is similar to that of Proposition 2-3, case II.

Case V. $\tau_{N S_{o}}<\tau_{N S_{l}}$, and after joining, $S_{l}$ is excluded. 


\section{Yuan Zi}

The condition for $S_{l}$ to stop participating in GVCs is $\frac{\tau_{N S_{h} w_{S}^{*}}}{\tau_{N S_{l}}}<\frac{1}{a}$. Before the new South joins, the wage difference between $S_{h}$ and $S_{l}$ satisfy the proportionality condition: $\tau_{N S_{h}} w_{S_{h}}=\tau_{N S_{l}} w_{S_{l}}$. Since $w_{S_{l}} \geq \frac{1}{a}$, then $w_{S_{h}}^{*}<w_{S_{l}}$. For the rest of inside South, given that they continue to participate in production sharing, wage proportionality implies that their wage decreases as well; if they exit production sharing, their wage decreases to $\frac{1}{a}$.

The five cases above exhausts all possibilities. Hence I complete the proof of Proposition 2-3.

Proof of Proposition 2-4. Given the proof in Proposition 2-3, step1, the problem can be characterized as in the two country setting, with the South size being the trade friction-weighted sum of all South's sizes. Thus, the results of Proposition 2-4 directly follow that of Propositions 1-3 and 1-4.

Proof of Proposition 2-3. Index countries inside of the value chain as $c \in C \equiv\{1, \ldots, C\}$. Again, countries are ordered so that $\lambda_{c}$ is strictly decreasing in $c$. Let $S_{c-1}$ denote the cutoff stage between country $c$ and $c-1, \tau_{c}$ denote the trade friction between country $c$ and $c-1, N_{c} \equiv S_{c}-S_{c-1}$ denote the measure of stages performed by country $c$ within the supply chain, and $P_{c} \equiv P\left(S_{c}\right)$ as the price of country $c$ 's exports. Then the pattern of vertical specialization, export levels, wages, and export prices can be expressed as the following system of first-order linear difference equations in a similar fashion to Lemma 2-4:

$$
\begin{gathered}
w_{c}=\theta \tau_{c-1} w_{c-1}+\theta \tau_{c} P_{c}\left(\lambda_{c-1}-\lambda_{c}\right) \\
P_{c}=\theta \tau_{c-1} e^{\lambda_{c} N_{c}} P_{c-1}+\left(e^{\lambda_{c} N_{c}}-1\right)\left(\frac{w_{c}}{\lambda_{c}}\right) \\
S_{c}-S_{c-1} \equiv N_{c}=-\frac{1}{\lambda_{C}} \ln \left(1-\frac{\lambda_{c} L_{c}}{Q_{c-1} / \theta \tau_{c-1}}\right) \\
Q_{c}=\frac{1}{\theta \tau_{c-1}} e^{-\lambda_{c} N_{c}} Q_{c-1}
\end{gathered}
$$

Above equations hold for all $c \in \boldsymbol{C}$ with boundary conditions $S_{0}=0, S_{C}=1, P_{0}=0, P_{C}=1$.

Next, I decompose the proof of Proposition 2-3 into three steps. I first show that a decrease in $\theta$ increases the measure of stages $N_{c}$ performed by countries with $c<c_{1}$ and decreases the measure of stages $N_{c}$ performed by countries with $c>c_{1}$. Second, I show that a decrease in $\theta$ leads all countries to move up the value chain.

Step1. If $\theta^{\prime}<\theta$, then there exits $1<c_{1} \leq C$ such that $N_{c}^{\prime}>N_{c}$ if $c \leq c_{1}$, and $N_{c}^{\prime}<N_{c}$ if $c>c_{1}$. Equations (68) and (69), combined with the definition of $N_{c}$ imply:

$$
N_{c}=-\frac{1}{\lambda_{C}} \ln \left[1-\frac{\lambda_{c} L_{c} \theta \tau_{c-1}}{\lambda_{c-1} L_{c-1}}\left(e^{\lambda_{c-1} N_{c-1}}-1\right)\right]
$$

After some algebra, one can check that $\partial N_{c} / \partial N_{c-1}>0$ and $\partial N_{c} / \partial \theta>0$. Since $\theta^{\prime}<\theta$, equation (70) explains if $N_{c-1}^{\prime} \leq N_{c-1}$ for $c>1$, then $N_{c}^{\prime}<N_{c}$. Therefore, if $N_{1}^{\prime} \leq N_{1}$, then $N_{c}^{\prime}<N_{c}$ for all $c>1$, 
which contradicts the fact that $\sum_{1}^{C} N_{c}=1$. Therefore this implies the existence of $1<c_{1} \leq C$ such that $N_{c}^{\prime}>N_{c}$ if $c<c_{1}$, and $N_{c}^{\prime}<N_{c}$ if $c>c_{1}$.

Step2. If $\theta^{\prime}<\theta$, then $S_{c}^{\prime}>S_{c}$ for all $c \in\{1, \ldots, C-1\}$.

By step1 of the proof and the definition of $N_{c}, S_{c}^{\prime}>S_{c}$ if $c \leq c_{1}$. If $c_{1}=C$, the proof is complete. If $c_{1}<C$, then denote the first country that has $S_{c}^{\prime} \leq S_{c}$ as $c_{2}$, and $c_{1} \leq c_{2}<C$, then it must be that $N_{c_{2}}^{\prime}<N_{c_{2}}$. By the results of step1, this implies $N_{c}^{\prime}<N_{c}$ if $c>c_{2}$, which in turn means that $\sum_{1}^{C} N_{c}{ }^{\prime}=$ $S_{c_{2}}^{\prime}+\sum_{c_{2}+1}^{C} N_{c}{ }^{\prime}<S_{c_{2}}+\sum_{c_{2}+1}^{C} N_{c}=1$. Hence I prove by contradiction that there exist no $c \in\left[c_{1}, C\right)$ such that $S_{c}^{\prime} \leq S_{c}$.

Proofs of Lemmas 4 and 5, and Propositions 2-1, 2-2, 3-1, and 3-2 should be straightforward given the explanation provided in the text.

\section{References}

Akamatsu, Kaname. 1962. "A Historical Pattern of Economic Growth in Developing Countries." The Developing Economies, 1(s1), 3-25.

Antràs, Pol and Davin Chor. 2012. "Organizing the Global Value Chain," National Bureau of Economic Research,

Antràs, Pol and Esteban Rossi-Hansberg. 2008. "Organizations and Trade," National Bureau of Economic Research,

Baldwin, Richard. 2006. "Globalisation: The Great Unbundling (S)." Economic Council of Finland, 20. . 2008. "Managing the Noodle Bowl: The Fragility of East Asian Regionalism." The Singapore Economic Review, 53(03), 449-78. . 2011. "Trade and Industrialisation after Globalisation's 2nd Unbundling: How Building and Joining a Supply Chain Are Different and Why It Matters." National Bureau of Economic Research Working Paper Series, No. 17716(published as Richard Baldwin. "Trade and Industrialisation after Globalisation's Second Unbundling: How Building and Joining a Supply Chain are Different and Why it Matters," in Robert C. Feenstra and Alan M. Taylor, editors, "Globalization in an Age of Crisis: Multilateral Economic Cooperation in the Twenty-First Century" University of Chicago Press (2013)).

. 2012. "Wto 2.0: Global Governance of Supply-Chain Trade." CEPR Policy Insight, No.64.

Baldwin, Richard and Javier Lopez-Gonzalez. 2013. "Supply-Chain Trade: A Portrait of Global Patterns and Several Testable Hypotheses." National Bureau of Economic Research Working Paper Series, No. 18957.

Baldwin, Richard and Anthony J Venables. 2013. "Spiders and Snakes: Offshoring and Agglomeration in the Global Economy." Journal of international Economics.

Bjorvatn, Kjetil and Nicola Daniele Coniglio. 2012. "Big Push or Big Failure? On the Effectiveness of Industrialization Policies for Economic Development." Journal of the Japanese and International Economies, 26(1), 129-41.

Costinot, Arnaud. 2009. "On the Origins of Comparative Advantage." Journal of international Economics, 77(2), 255-64.

Costinot, Arnaud; Jonathan Vogel and Su Wang. 2013. "An Elementary Theory of Global Supply Chains." The Review of Economic Studies, 80(1), 109-44. 
Dixit, Avinash K and Gene M Grossman. 1982. "Trade and Protection with Multistage Production." The Review of Economic Studies, 49(4), 583-94.

Dixit, Avinash K and Joseph E Stiglitz. 1977. "Monopolistic Competition and Optimum Product Diversity." The American Economic Review, 67(3), 297-308.

Easterly, William. 2006. "Reliving the 1950s: The Big Push, Poverty Traps, and Takeoffs in Economic Development." Journal of Economic Growth, 11(4), 289-318.

Fally, Thibault and Russell Hillberry. 2013. "Quantifying Upstreamness in East Asia: Insights from a Coasian Model of Production Staging," mimeo,

Findlay, Ronald. 1978. "An" Austrian" Model of International Trade and Interest Rate Equalization." The Journal of Political Economy, 989-1007.

Garicano, Luis. 2000. "Hierarchies and the Organization of Knowledge in Production." Journal of Political Economy, 108(5), 874-904.

Gereffi, Gary; John Humphrey and Timothy Sturgeon. 2005. "The Governance of Global Value Chains." Review of international political economy, 12(1), 78-104.

Harms, Philipp; Oliver Lorz and Dieter Urban. 2012. "Offshoring Along the Production Chain." Canadian Journal of Economics/Revue canadienne d'économique, 45(1), 93-106.

Hummels, David; Jun Ishii and Kei-Mu Yi. 2001. "The Nature and Growth of Vertical Specialization in World Trade." Journal of international Economics, 54(1), 75-96.

Hummels, David; Dana Rapoport and Kei-Mu Yi. 1998. "Vertical Specialization and the Changing Nature of World Trade." Economic Policy Review, 4(2).

Johnson, Robert C and Guillermo Noguera. 2012a. "Fragmentation and Trade in Value Added over Four Decades." National Bureau of Economic Research Working Paper Series, No. 18186.

. 2012b. "Proximity and Production Fragmentation." The American Economic Review, 102(3), 407-11.

Kikuchi, Tomoo; Kazuo Nishimura and John Stachurski. 2012. "Coase Meets Tarski: New Insights from Coase's Theory of the Firm." KIER Discussion Paper, 828.

Klier, Thomas $\mathbf{H}$ and James M Rubenstein. 2008. Who Really Made Your Car?: Restructuring and Geographic Change in the Auto Industry. WE Upjohn Institute.

Kline, Patrick and Enrico Moretti. 2011. "Local Economic Development, Agglomeration Economies and the Big Push: 100 Years of Evidence from the Tennessee Valley Authority."

Kojima, Kiyoshi. 2000. "The "Flying Geese" Model of Asian Economic Development: Origin, Theoretical Extensions, and Regional Policy Implications." Journal of Asian Economics, 11(4), 375-401.

Koopman, Robert; William Powers; Zhi Wang and Shang-Jin Wei. 2010. "Give Credit Where Credit Is Due: Tracing Value Added in Global Production Chains." National Bureau of Economic Research Working Paper Series, No. 16426.

Kremer, Michael. 1993. "The O-Ring Theory of Economic Development." The Quarterly Journal of Economics, 108(3), 551-75.

Krugman, Paul and Anthony J Venables. 1995a. "Globalization and the Inequality of Nations." The Quarterly Journal of Economics, 110(4), 857-80.

- 1990. "Integration and the Competitiveness of Peripheral Industry," CEPR Discussion Papers, . 1995b. "The Seamless World: A Spatial Model of International Specialization," National Bureau of Economic Research, 
Levitt, Steven D; John A List and Chad Syverson. 2013. "Toward an Understanding of Learning by Doing: Evidence from an Automobile Assembly Plant." Journal of Political Economy, 121(4), 643-81.

Lewis, W Arthur. 1954. "Economic Development with Unlimited Supplies of Labour." The manchester school, 22(2), 139-91.

Lindauer, David L. and Lant Pritchett. 2002. "What's the Big Idea? The Third Generation of Policies for Economic Growth [with Comments]." Economia, 3(1), 139.

Magruder, Jeremy R. 2013. "Can Minimum Wages Cause a Big Push? Evidence from Indonesia." Journal of Development Economics, 100(1), 48-62.

Malerba, Franco. 1992. "Learning by Firms and Incremental Technical Change." The Economic Journal, 845-59.

Murphy, Kevin M; Andrei Shleifer and Robert W Vishny. 1989. "Industrialization and the Big Push." The Journal of Political Economy, 97(5), 1003-26.

Nocke, Volker and Stephen Yeaple. 2008. "An Assignment Theory of Foreign Direct Investment." The Review of Economic Studies, 75(2), 529-57.

OECD. 2013. Interconnected Economies. OECD Publishing. . 2007. Staying Competitive in the Global Economy. OECD Publishing.

Ohnsorge, Franziska and Daniel Trefler. 2007. "Sorting It Out: International Trade with Heterogeneous Workers." Journal of Political Economy, 115(5), 868-92.

Ottaviano, Gianmarco and Jacques-François Thisse. 2004. "Agglomeration and Economic Geography." Handbook of regional and urban economics, 4, 2563-608.

Rauch, James E. 2010. "Development through Synergistic Reforms." Journal of Development Economics, 93(2), 153-61.

Rosenstein-Rodan, Paul N. 1943. "Problems of Industrialisation of Eastern and South-Eastern Europe." The Economic Journal, 53(210/211), 202-11.

Sanyal, Kalyan K and Ronald W Jones. 1982. "The Theory of Trade in Middle Products." The American Economic Review, 72(1), 16-31.

Sobel, Joel. 1992. "How to Count to One Thousand." The Economic Journal, 102(410), 1-8.

Spencer, Barbara J and Ronald W Jones. 1992. "Trade and Protection in Vertically Related Markets." Journal of international Economics, 32(1), 31-55.

Thornton, Rebecca Achee and Peter Thompson. 2001. "Learning from Experience and Learning from Others: An Exploration of Learning and Spillovers in Wartime Shipbuilding." American Economic Review, 1350-68.

Yeaple, Stephen Ross. 2005. "A Simple Model of Firm Heterogeneity, International Trade, and Wages." Journal of international Economics, 65(1), 1-20.

Yi, Kei-Mu. 2003. "Can Vertical Specialization Explain the Growth of World Trade?" Journal of Political Economy, 111(1), 52-102. 
Centre for Trade AND ECONOMIC INTEGRATION (CTEI)

The Centre for Trade and Economic Integration fosters world-class multidisciplinary scholarship aimed at developing solutions to problems facing the international trade system and economic integration more generally. It works in association with public sector and private sector actors, giving special prominence to Geneva-based International Organisations such as the WTO and UNCTAD. The Centre also bridges gaps between the scholarly and policymaking communities through outreach and training activities in Geneva.

www.graduateinstitute.ch/ctei 